\title{
Symposium review: The importance of the ruminal epithelial barrier for a healthy and productive cow*
}

\author{
Jörg R. Aschenbach, ${ }^{1} \dagger$ Qendrim Zebeli, ${ }^{2}$ Amlan K. Patra, ${ }^{1,3}$ Gabriele Greco, ${ }^{1}$ Salah Amasheh, ${ }^{1}$ \\ and Gregory B. Penner ${ }^{4}$ \\ ${ }^{1}$ Institute of Veterinary Physiology, Freie Universität Berlin, 14163 Berlin, Germany \\ ${ }^{2}$ Institute of Animal Nutrition and Functional Plant Compounds, Department for Farm Animals and Veterinary Public Health, \\ University of Veterinary Medicine Vienna, 1210 Vienna, Austria \\ ${ }^{3}$ Department of Animal Nutrition, West Bengal University of Animal and Fishery Sciences, Belgachia, Kolkata 700037, India \\ ${ }^{4}$ Department of Animal and Poultry Science, University of Saskatchewan, Saskatoon, Saskatchewan, Canada, S7N 5A8
}

\section{ABSTRACT}

The stratified squamous ruminal epithelium is the main site for absorption of key nutrients (e.g., shortchain fatty acids; SCFA) and electrolytes (e.g., sodium and magnesium). The absorptive function has to be highly selective to prevent simultaneous entry of microbes and toxins from the rumen into the blood. As such, epithelial absorption is primarily transcellular, whereas the paracellular pathway appears rather tightly sealed. A network of tight junction (claudin-1, claudin-4, and occludin) and tight junction-associated proteins (e.g., zonula occludens) accomplishes the latter. When microbial fermentation activity is high such as with highly fermentable diets, rumen epithelial functions are often challenged by acidity, high osmolarity, toxins (e.g., endotoxin and histamine), and immune mediators (inflammatory mediators and cytokines) released during local and systemic inflammation. Epithelial damage by low $\mathrm{pH}$ in combination with high luminal SCFA concentrations is not immediately reversible and may initially aggravate upon return to physiological $\mathrm{pH}$. In contrast, barrier opening upon hyperosmolarity is acutely transient. The initial insults set by luminal acidity and SCFA and the increasing concentrations of microbial-associated molecular patterns such as lipopolysaccharides are key factors that trigger inflammation not only in the rumen but also in the hindgut (cecum and colon), which reach out to the liver and other organs, causing systemic inflammation. Low feed intake during parturition, transportation, heat stress, or disease is the second most relevant challenge for the

Received June 19, 2018.

Accepted October 4, 2018.

*Presented as part of the Ruminant Nutrition Platform Session: Rumen Function and Health at the ADSA Annual Meeting, Knoxville, Tennessee, June 2018.

†Corresponding author: joerg.aschenbach@fu-berlin.de ruminal epithelial barrier. The barrier opening is usually only transient and quickly restored upon refeeding. Due to a rapid, dose-dependent, and prolonged decrease in absorption capacity for SCFA, however, any feed restriction increases the odds for postrestriction subacute ruminal acidosis. Inflammation due to acidosis can be alleviated by supplemental thiamine, yeasts, and plant bioactive (phytogenic) compounds. Butyrate is used in weaning calves to support ruminal barrier development; however, excess butyrate may promote hyperkeratosis, parakeratosis, and epithelial injury in the fully developed rumen of adult cows. Further research is needed to enhance the understanding of the various factors that counteract barrier impairment and help barrier restoration during acidogenic feeding, especially when concurring with unavoidable periods of feed restriction. Key words: epithelial barrier, rumen, short-chain fatty acid, subacute ruminal acidosis, tight junction

\section{INTRODUCTION}

Health and productivity are inherently linked in farm animals. In an ethical sense, health and productivity of farm animals can be seen as partly complementing indicators of successful bidirectional integration of genetic merit with environmental factors. Conversely, an increasing disease incidence and poor performance may indicate that our capabilities to create the animals' environment do not fit their genetic merit, possibly implying that human ambitions for the latter were set not compliant with the former (Kunzmann, 2018). For high-yielding dairy cows, it is widely acknowledged that our capabilities to process and deliver the right feed in the right form and right amount at the right frequency (Humer et al., 2018b) is vital for integrating the limitations of forestomach fermentation with a genetic merit to deliver milk with a potential to feed 5 or even more offspring. The resulting nutritional challenge is to convert a forestomach that has evolutionarily adapted 
to slow fermentation of rather poor-quality feed (Hoffmann and Schnorr, 1982) into a fast high-throughput fermenter with maximized energy and protein yields. Of the many things that can go wrong during that journey, the frequently occurring damage to the ruminal epithelium (RE) barrier is of key importance (Liu et al., 2013; Meissner et al., 2017; Greco et al., 2018). This damage crucially determines whether the negative consequences of highly accelerated or possibly upset fermentation remain contained within the forestomach or, alternatively, are carried over to the host and interfere with health and productivity (Klevenhusen et al., 2013; Liu et al., 2013).

The scenario becomes even more complex when acknowledging that the $\mathrm{RE}$ cannot be maximized for barrier function but has to fulfil equally important transport functions in parallel. The forestomach microbiota effectively convert carbohydrates to short-chain fatty acids (SCFA; Bugaut, 1987; Allen, 1997). In high-yielding dairy cows, the production rates of SCFA may exceed $100 \mathrm{~mol} / \mathrm{d}$ (Aschenbach et al., 2011), which is equivalent to $>7 \mathrm{~kg}$ of pure acids/d. Such acidity cannot be neutralized by saliva only. The acids need to be rapidly and effectively absorbed to prevent a severe decrease in ruminal $\mathrm{pH}$ (Aschenbach et al., 2011). Our previous research has shown that the efficiency of SCFA absorption from the forestomach counteracts the development of the subacute form of ruminal acidosis, SARA (Penner et al., 2009). Apart from SCFA, the rumen is also a key organ for the absorption of several electrolytes, such as $\mathrm{Na}^{+}, \mathrm{Cl}^{-}$(Gäbel et al., 1993; Dua et al., 1994), $\mathrm{Mg}^{2+}$ (Gäbel et al., 1993; MartínTereso and Martens, 2014; Martens et al., 2018), and, depending on availability and DCAD, $\mathrm{Ca}^{2+}$ (MartínTereso and Martens, 2014; Wilkens et al., 2016). To allow efficient absorption of these nutrients without the simultaneous entry of microbes, antigenic substances, and toxins from the rumen into the blood, the RE has an unusually strict separation between selective absorption via the transcellular route, whereas the paracellular pathway appears rather tightly sealed. Even the enormous flux of SCFA is channeled almost completely through the RE cells despite the huge challenges that this imposes on intracellular $\mathrm{pH}$ homeostasis (Müller et al., 2000; Gäbel et al., 2002; Aschenbach et al., 2011). In the present review, we analyze the current major challenges to the RE barrier with primary focus on SARA and periods of feed restriction. We discuss the direct effects on the RE barrier as well as their link to systemic effects. An understanding of these challenges and their sequela is of vital importance for safeguarding health and maintaining productivity in high-yielding dairy herds.

\section{CHARACTERISTICS OF THE RUMINAL EPITHELIAL BARRIER}

The barrier components of gastrointestinal (GI) epithelia include an epithelium-adapted microbiome interacting with an outer, continuously shedding mechanical barrier, the latter being mucus, cornified cells, or both. The mentioned barrier components protect the living epithelial cells from mechanical damages and act together with immunological (e.g., immune cells, antibodies) and chemical (e.g., pH, defensins) barrier components to restrict microbial, especially pathogen, invasion. Finally, a tight junction (TJ) barrier restricts invasion of microbes that were able to cross the mechanical barrier but, moreover, has a crucial function as a semiselective permeation barrier that prevents the uncontrolled entry of noxious molecules (Malago, 2015; Bäsler et al., 2016; Glover et al., 2016). If not stated otherwise, we use the term "RE barrier" mostly as a synonym for the TJ permeation barrier in the present review because of the crucial importance of the TJ barrier and because the available literature for the rumen mostly focuses on the functional relevance of this barrier component.

The RE is a keratinizing stratified squamous epithelium consisting of a stratum basale, where mitosis constantly replenishes cells and where ample mitochondrial ATP generation and its subsequent utilization by $\mathrm{Na}^{+} /$ $\mathrm{K}^{+}$-ATPase generate the electrochemical gradients for absorption and secretion (Graham and Simmons, 2005). The dividing cells of the stratum basale subsequently differentiate through the stratum spinosum and stratum granulosum to form an apical absorbing and secreting membrane with diverse transport proteins in the upper cell layer of the stratum granulosum (Graham and Simmons, 2005; Stumpff et al., 2011; Stumpff, 2018). The terminal differentiation of RE cells further includes cornification that starts with keratohyalin generation already in the stratum spinosum. It culminates when stratum granulosum cells convert to transition cells that degrade their cell organelles (e.g., nucleus, endoplasmatic reticulum) as well as TJ to become stratum corneum cells that are interconnected punctiform by desmosomes and, in the RE specifically, by claudin (CLDN)-7 (Lavker and Matoltsy, 1970; Eckhart et al., 2013; Greco et al., 2018).

To understand the realization of the dual function of the $\mathrm{RE}$ as an effective permeation barrier on the one hand and an effectively absorbing and secreting body surface on the other hand, it is important to acknowledge that plenty of gap junctions interlink cells of the basal, spinous, and granular strata. Consequently, the cells of these strata form a functional syncytium (Gra- 
ham and Simmons, 2005). The most luminal cell layer of this functional syncytium in the stratum granulosum is tightly interconnected by a 3 -dimensional network of the TJ proteins that includes CLDN-1, CLDN-4, and occludin (Stumpff et al., 2011; Meissner et al., 2017; Greco et al., 2018). Tight junction-associated proteins such as zonula occludens-1 support the mentioned TJ proteins (Graham and Simmons, 2005). Although most of these proteins are also identifiable in deeper cell layers, it is in the upper layer of the stratum granulosum where they form such a TJ network that functionally builds the permeation barrier (Henrikson and Stacy, 1971; Meissner et al., 2017; Greco et al., 2018). The TJ proteins identified so far (occludin, CLDN-1, and CLDN-4) all transfer tightness to a TJ barrier (Markov et al., 2015), whereas claudins that transfer leakiness to a TJ, specifically CLDN-2 and CLDN-10, appear to be absent in the RE (Stumpff et al., 2011). Accordingly, the paracellular barrier of $\mathrm{RE}$ is comparatively tight for passive solute permeation (Penner et al., 2014) as long as it is not challenged. Conversely, a marked increase in RE permeability occurs when, for example, ruminal acidosis decreases the abundance and TJ localization of CLDN-1, CLDN-4, and occludin (Liu et al., 2013; Greco et al., 2018).

\section{CHALLENGES IMPOSED BY HIGHLY FERMENTABLE DIETS}

\section{Role of SARA}

The feeding of rapidly fermentable grain-rich diets to high-yielding dairy cows is necessary to minimize metabolic disturbances in early lactation (Aschenbach et al., 2010) and to maximize milk production in a cost-effective manner over the whole lactation period (Jørgensen et al., 2016; Humer et al., 2018b). However, such feeding practices may overwhelm the digestive physiology of cattle by impairing chewing and rumination activity, lowering the flow of alkaline saliva and, hence, rumen buffering (Aschenbach et al., 2011). Furthermore, they may cause major disturbances in the ruminal ecosystem that affect, for example, the survival and selection of gram-negative bacteria (GNB; Khafipour et al., 2009a, 2011). Greater rates of fermentation acid production drive the reduction in ruminal $\mathrm{pH}$ causing SARA (Aschenbach et al., 2011). The simultaneous decrease in chewing and rumination activity reduces the flow of saliva and the supply of salivary buffer entering the rumen, thus increasing the reliance on SCFA absorption and passage of acid out of the rumen as strategies to buffer ruminal digesta (Allen, 1997; Dijkstra et al., 2012). A direct implication of feeding highly fermentable diets is a high risk of ruminal (Penner et al., 2011) and systemic (Zebeli and Metzler-Zebeli, 2012; Hua et al., 2017) metabolic disorders. Of metabolic disorders, SARA is considered a major animal health and welfare issue in intensive ruminant production systems (Plaizier et al., 2008). Indeed, SARA is associated with lowered feed efficiency and significant production losses (Desnoyers et al., 2009), likely explained by decreased fermentation efficiency in the rumen (Zebeli et al., 2012) but also by systemic inflammation and related systemic effects of SARA. Subacute ruminal acidosis is initiated by a chain of metabolic alterations in the rumen (Khafipour et al., 2011; Steele et al., 2016; Hua et al., 2017) characterized by increased SCFA concentration, low $\mathrm{pH}$, and ruminal hyperosmolarity (Owens et al., 1998; Hernández et al., 2014; Humer et al., 2018a). These alterations further lead to the release of toxic metabolites (e.g., biogenic amines; Pilachai et al., 2012) and large amounts of LPS and other microbial associated molecular patterns (MAMP) in the ruminal fluid (Ametaj et al., 2010; Garcia et al., 2017). All of these metabolic alterations have the potential to damage the $\mathrm{RE}$ barrier to facilitate the translocation of proinflammatory signals (e.g., LPS and histamine; Figure 1), which is further analyzed in the following subsections.

\section{Influence of SARA on the RE Barrier}

Substantial evidence supports the idea that grainrich diets and SARA are involved in disruption of the RE barrier. For example, the study by Steele et al. (2011) showed that desmosomal proteins were downregulated during a gradual adaptation to diets containing $65 \%$ grain. In another study, a proteome analysis conducted by Bondzio et al. (2011) revealed that 40 proteins of the RE associated with key functions such as cellular stress, metabolism, and differentiation were upregulated, whereas 20 other proteins were downregulated following a 2-d induction of SARA. After 6 wk of feeding the SARA diet, however, these authors observed that only 11 proteins of RE were upregulated and 3 were downregulated, suggesting an adaptational process of RE proteins to high-concentrate diets. It has also been demonstrated that a high plane of nutrition and the resulting acidotic stress result in depletion of key protective factors of the RE cells, rendering them more vulnerable to cellular damage and inflammation (Hollmann et al., 2013). In another study, Schurmann et al. (2014) imposed a rapid dietary change from a hay-based diet to one that contained $50 \%$ concentrate. Although acidosis was not induced in this study, tissue conductance, as a measure of permeability, linearly increased as calves were fed the $50 \%$ concentrate diet for $3,7,14$, and $21 \mathrm{~d}$. They also observed linear increases in the serosal-to-mucosal flux of $\mathrm{Na}^{+}$, further support- 


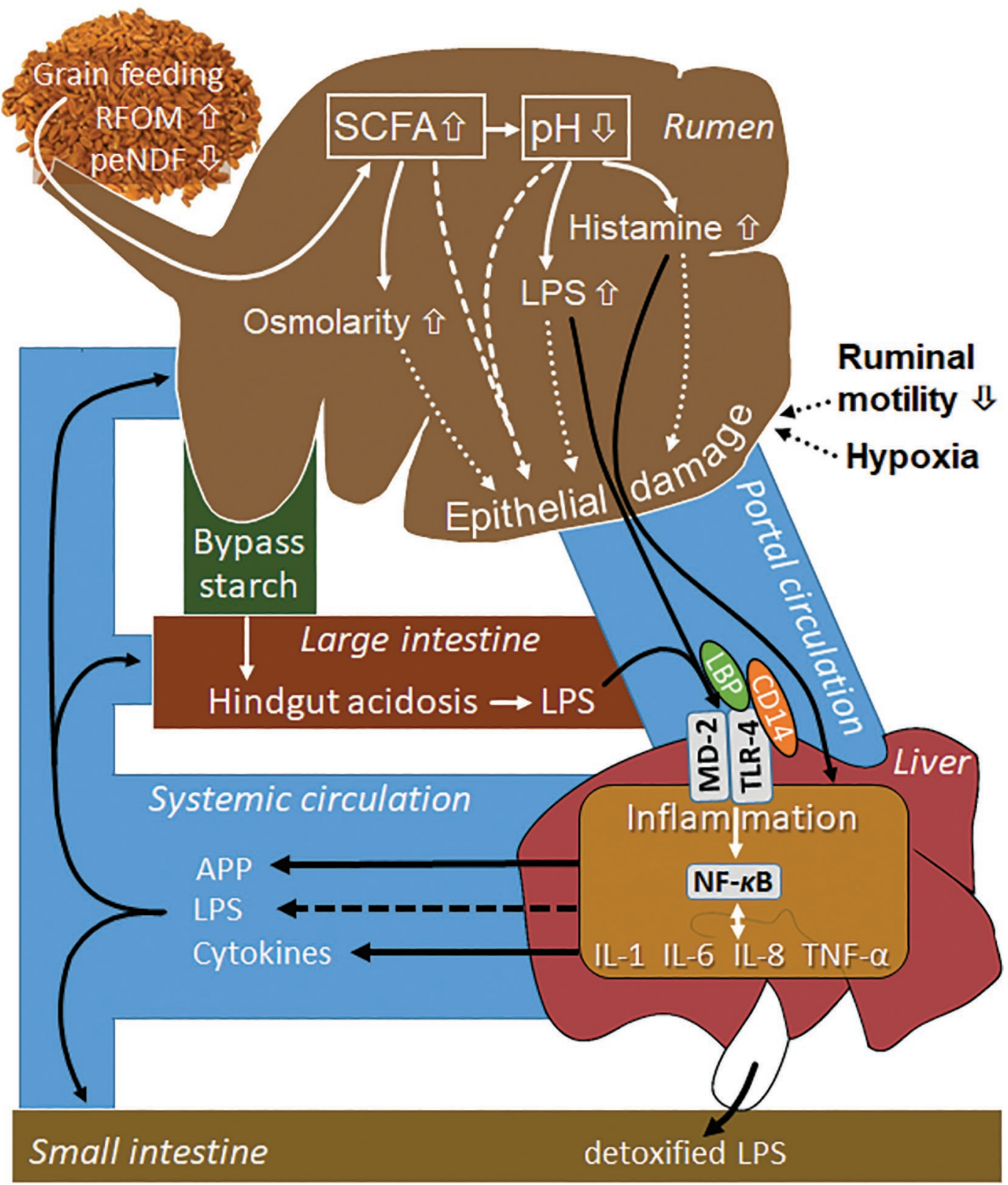

Figure 1. Model visualizing the triggers of ruminal epithelial barrier damage and the subsequent activation of systemic inflammation. Grainrich diets favor a high intake of rumen-fermentable OM (RFOM) that, if not properly balanced with physically effective NDF (peNDF), leads to excessive production of short-chain fatty acids (SCFA; possibly also lactic acid) with a parallel decrease in $\mathrm{pH}$ and an increase in ruminal osmolarity. These factors, especially the combination of low pH and SCFA, damage the ruminal epithelium progressively over time. The low $\mathrm{pH}$ also shifts bacterial metabolism toward the production of biogenic amines, including histamine, and provides unfavorable growth conditions for most gram-negative bacteria that release large amounts of LPS into the ruminal fluid. Epithelial inflammation by histamine and LPS, low rumen motility, and hypoxia may aggravate the epithelial damage. Histamine, LPS, and possibly live bacteria cross the damaged epithelial barrier and reach the liver via the portal circulation, where they elicit inflammation, most prominently, via the nuclear factor (NF)- $\kappa \mathrm{B}$ pathway. Lipopolysaccharides play a dominant role in this inflammation, and their signal is perceived after complexing with LPS-binding protein (LBP) and cluster of differentiation 14 (CD14) by binding to the toll-like receptor 4/protein myeloid differentiation-2 (TLR-4/MD-2) receptor complex. Apart from their local effects, proinflammatory cytokines such as IL-1, IL-6, IL-8, and tumor necrosis factor (TNF)- $\alpha$ spill over into the systemic circulation to induce systemic inflammation together with the released acute phase proteins (APP). The liver finally inactivates LPS and releases it via bile into the small intestine. However, if the detoxifying capacity of the liver is overtaxed, LPS may also enter the systemic circulation to further promote systemic inflammation. The systemic inflammation interferes with barrier and transport functions of all gastrointestinal epithelia. If the provided grain contains a large proportion of bypass starch, acidosis may concurrently or alternatively be elicited in the hindgut, where comparable pathophysiological mechanisms lead to epithelial damage and LPS and histamine absorption with subsequent systemic inflammation. A direct flow of bypass starch to the large intestine is visualized in the model for didactic reasons, although it is well acknowledged that this bypass naturally occurs via the small intestine. 
ing an increase in ion permeability in response to dietary change. The tendency for mannitol flux, a more direct measure for paracellular permeability, in the same calves (Walpole et al., 2015) to increase further suggests that changes were attributable to an opening of the paracellular space. As such, some of the changes observed resemble changes commonly reported during acidosis, suggesting that increased provision of rumenfermentable OM, especially starch, may modulate RE barrier function even in the absence of ruminal acidosis.

\section{Barrier Effects of Low pH, SCFA, and Hyperosmolarity}

The mechanisms behind the effects of SARA on the RE barrier have been partially elucidated. From an acute standpoint, it is clear that acidification of the RE plays a crucial role and decreases barrier function as indicated by increased permeability to paracellular permeability markers such as mannitol (Penner et al., 2010; Wilson et al., 2012). Only recently has it become clear that the simultaneously elevated SCFA concentration in the rumen plays a significant role as well. Experiments by Meissner et al. (2017) and Greco et al. (2018) demonstrated that increases in permeability of the $\mathrm{RE}$ are moderate when luminal $\mathrm{pH}$ is lowered to $\mathrm{pH} 5.1$ for several hours. However, the same $\mathrm{pH}$ induced significant decreases in protein abundance and TJ localization of TJ proteins in the presence of SCFA, coupled with profound increases in RE permeability (Figure 2). This indicates that the effect of luminal acidification requires potentiation by the co-presence of SCFA to modulate barrier function effectively (Meissner et al., 2017; Greco et al., 2018). Evidence for the effect of ruminal acidosis to alter barrier function has been partially confirmed in vivo using lactulose as a permeability marker (Minuti et al., 2014). In another study, goats were fed a high-grain diet, with 45 and $20 \%$ of the diet coming from corn and wheat, respectively, for $7 \mathrm{wk}$ (Liu et al., 2013). In that study, the authors reported reduced ruminal $\mathrm{pH}$, increased SCFA concentration, and detectable free plasma LPS in the ruminal acidosis group only and reductions in CLDN-4, occludin, and zonula occludens with grain feeding relative to the hayfed control. They also noted increased proinflammatory cytokine abundance, which suggests that, in vivo, low $\mathrm{pH}$ and high SCFA concentration may act coordinately with proinflammatory signals. Furthermore, although the outcome arising from high-grain feeding was well described, it is not clear whether consequences were the result of high-grain feeding or the ruminal acidosis that was induced, presumably repeatedly, with the dietary management. Similar methodological concerns have been raised challenging the interpretation of many studies regarding ruminal acidosis using a variety of induction protocols (Humer et al., 2018a). As such, studies ex vivo or in vitro are essential for isolating the contribution of those multifaceted effects occurring in vivo (Meissner et al., 2017; Greco et al., 2018).
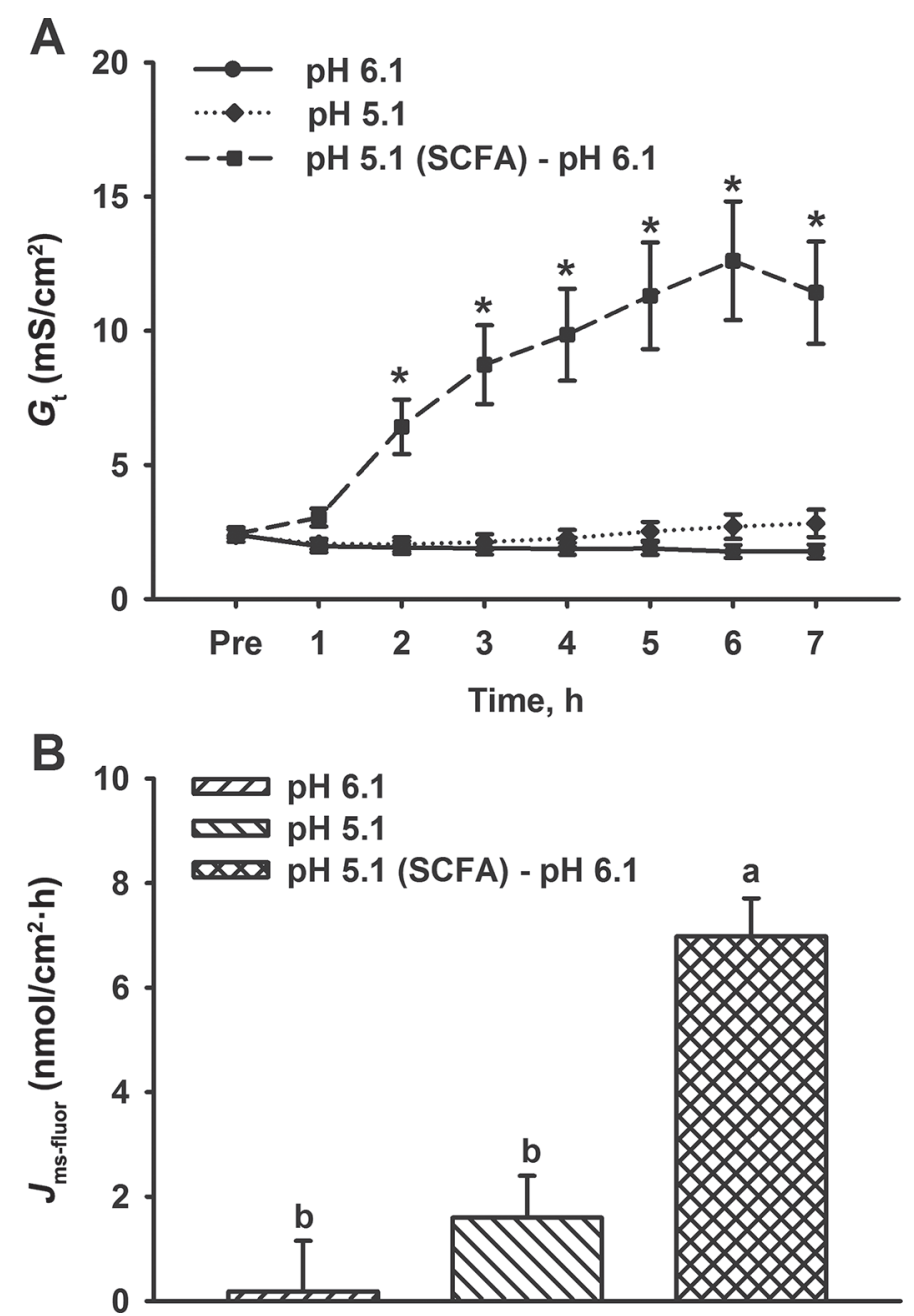

Figure 2. Low mucosal $\mathrm{pH}$ requires short-chain fatty acids (SCFA) to effectively damage the ruminal epithelial barrier. Barrier function was assessed based on tissue conductance $\left(G_{t}\right)$ and fluorescein flux rates from the mucosal to the serosal side $\left(J_{\text {ms-fluor }}\right)$. Ussing chamber experiments with ruminal tissues were performed under $3 \mathrm{pH}$ conditions: incubation at mucosal (i.e., luminal) $\mathrm{pH} 6.1$ or $\mathrm{pH} 5.1$, both in the absence of SCFA for $7 \mathrm{~h}$, or mucosal pH 5.1 with $100 \mathrm{~m} M$ SCFA (60 $\mathrm{m} M$ acetate, $30 \mathrm{~m} M$ propionate, and $10 \mathrm{~m} M$ butyrate) for the first $2 \mathrm{~h}$ followed by mucosal $\mathrm{pH} 6.1$ without SCFA for the remaining $5 \mathrm{~h}$. (A) Values for $G_{\mathrm{t}}$ were recorded each minute and arithmetically pooled over $1 \mathrm{~h}$. Pooled values are presented as mean values \pm SEM. $* P<$ 0.05 compared with the preincubation value. (B) Fluorescein flux rates were measured hourly. They are summarized as LSM + SEM across periods 3 through 7 because the factor flux period $(P=0.87)$ and the mucosal incubation conditions $\times$ flux period interaction $(P=0.99)$ were not significant upon 2-way ANOVA. Columns that do not share a common letter (a or b) are significantly different $(P<0.01 ; \mathrm{n}=8-12)$. From Meissner et al., 2017. 
The contribution of hyperosmolarity to RE barrier integrity has also been studied and confirmed ex vivo by exposing isolated pieces of the RE to luminal hyperosmolarity. Luminal hyperosmolarity results from the accumulation of fermentation products in the rumen when their absorption cannot keep pace with their production and is a frequent occurrence during SARA (Owens et al., 1998; Steele et al., 2011). Hyperosmolarity induces an immediate increase in paracellular marker fluxes across the RE ex vivo (Schweigel et al., 2005; Lodemann and Martens, 2006; Penner et al., 2010). This change in RE barrier has been explained by cell shrinkage with widening of the paracellular spaces (Lodemann and Martens, 2006), and, in contrast to acidosis-induced RE damage, it is usually reversible upon return to normotonic ruminal conditions (Lodemann and Martens, 2006; Penner et al., 2010). However, one experiment in which hyperosmolarity was induced by ruminal hyperosmolar potassium chloride solution infusion demonstrated that hyperosmolarity, in context with other challenges, can also promote cell destruction as evidenced by phagocytotic inclusions of cell debris in RE dendritic cells (Gemmell, 1973).

\section{Ruminal Release and Local Effects of Endotoxin and Other MAMP}

Of the MAMP generated in the rumen during SARA, cell-free endotoxin has attracted special interest (Plaizier et al., 2012; Garcia et al., 2017). Endotoxin or LPS is an abundant proinflammatory molecule of the outer leaflet of the cell wall of GNB. Zhao et al. (2018) showed that SARA increased the LPS concentration in ruminal fluid and blood, which stimulated the nuclear factor (NF)- $\kappa \mathrm{B}$ and mitogen-activated protein kinase inflammatory pathways and upregulated the expression and production of proinflammatory cytokines [i.e., tumor necrosis factor (TNF)- $\alpha$, IL-6, and IL-1 $\beta$ ] in RE. Ametaj et al. (2010), using a metabolomic approach, demonstrated that feeding large amounts of concentrate (up to 60\%) in the diet increased not only endotoxins in the ruminal fluid (up to 14-fold) but also the release of various other chemical compounds. This event was associated with greater severity of systemic inflammation in cows, thus indicating involvement of multiple diet-host-microbial factors in the disruption of the barrier functions of the host's epithelial lining. Although LPS has received the vast majority of the focus, other components such as flagellin, lipoteichoic acid, and microbial DNA also have the potential to induce a proinflammatory response, at least in other epithelia (Garcia et al., 2017). The current view is that with low ruminal $\mathrm{pH}$, proliferation of potentially pathogenic strains of GNB with certain virulence genes (e.g., Escherichia coli) and presence of their products (most likely SCFA, cell-free LPS, biogenic amines, and ethanol) negatively affect RE cadherins, contributing to the increase in permeability in the reticulorumen (Zebeli and Metzler-Zebeli, 2012).

It should be noted, however, that not only the concentration of endotoxin in ruminal fluid but also its toxicity play a role in the induction of inflammation. For example, compared with other GNB found in the rumen of cattle such as Megasphaera elsdenii, Fibrobacter succinogenes, Prevotella spp., and Bacteroides spp., the endotoxin of $E$. coli is much more toxic (Hurley, 1995). Therefore, the pathophysiology of SARA and the disruption of the RE barrier, as well as the activation of systemic inflammation, are expected to be greater when LPS of $E$. coli predominates in the rumen due to their greater virulence potential compared with other GNB (Khafipour et al., 2011). This hypothesis is supported by data of the study by Khafipour et al. (2011). They suggested that the numbers of E. coli with virulence factor genes for adhesion and biofilm formation increase markedly in the rumen under the low ruminal $\mathrm{pH}$ conditions induced by a grain-rich diet, indicating a role for them to facilitate the disruption of the barrier function of the RE.

\section{Ruminal Release and Local Effects of Biogenic Amines}

The release of biogenic amines, especially of histamine, in the ruminal fluid of acutely acidotic ruminants and their possible implications in local and systemic effects of ruminal acidosis is one of the very early findings of experimental acidosis research (Ahrens, 1967; Irwin et al., 1979; Suber et al., 1979). In addition, later studies confirmed a negative relationship between ruminal histamine concentration and ruminal $\mathrm{pH}$ for the moderate forms of acidosis (i.e., SARA; Pilachai et al., 2012). Aschenbach et al. (1998) were the first to show that application of histamine in relevant dosages (10 and $100 \mu M$ ) impairs differentiation of RE cells in culture, which may result in impaired RE function and barrier integrity. Recently, histamine has further been shown to activate the inflammatory pathway of cultured RE cells via NF-кB (Sun et al., 2017), which perceivably has consequences for RE function and integrity.

\section{Decrease of Epithelial Transport Function During SARA}

It is well known that moderate decreases in ruminal $\mathrm{pH}$, within physiological limits, stimulate the RE ab- 
sorption of $\mathrm{Na}^{+}$(Gäbel et al., 1991) and SCFA (Dijkstra et al., 1993; Aschenbach et al., 2009). By contrast, Gaebel et al. (1987, 1989) demonstrated that more severe decreases in luminal $\mathrm{pH}$ (to $\mathrm{pH} 4.8$ in vivo and $\mathrm{pH} 5.5$ ex vivo, respectively) lead to rapid decreases in the absorption of electrolytes $\left(\mathrm{Na}^{+}, \mathrm{Cl}^{-}\right.$, or $\left.\mathrm{Mg}^{2+}\right)$ across the RE. Studies that are more recent evidenced the latter also for SCFA; low ruminal $\mathrm{pH}$ (Wilson et al., 2012) and exposure to ruminal acidosis (Schwaiger et al., 2013) reduced SCFA absorption across the $\mathrm{RE}$, which parallels the decreases in barrier function (Penner et al., 2010; Wilson et al., 2012; Meissner et al., 2017). It is important to note that the increase in RE permeability and reduced SCFA absorption occur simultaneously and represent paracellular and transcellular processes, respectively. Morphologically evident swelling of RE cells and their mitochondria (Gaebel et al., 1989) verifies a global interference with diverse cellular functions and cellular energy utilization. Teleologically, the reduction for SCFA absorption in response to ruminal acidosis can be seen as a way to limit further intracellular acidification and the arising negative consequences of excessive intracellular SCFA supply on barrier function (Meissner et al., 2017; Greco et al., 2018). Hence, an effective barrier is necessary for both the controlled exposure and response to MAMP and other proinflammatory signals but also for efficient nutrient transport.

We must emphasize that the relationship between transport function and SARA is essentially bilateral; that is, SARA decreases RE transport function, but low RE transport function predisposes animals to SARA. Regarding the latter, Penner et al. (2009) were the first to show that sheep with lower absorptive capacity for SCFA responded to an oral glucose drench $(5 \mathrm{~g} / \mathrm{kg}$ of BW) with rapid development of SARA, whereas companion sheep with higher absorptive capacity regulated their ruminal $\mathrm{pH}$ above the SARA threshold. Later, Schlau et al. (2012) demonstrated that cows with genetically greater proneness to SARA (acidosis index of 61.7 vs. $13.5 \mathrm{pH} \times \mathrm{min} / \mathrm{kg}$ of $\mathrm{DMI}$ ) exhibited lower gene expression of $\mathrm{Na}^{+} / \mathrm{H}^{+}$-exchanger 3 in $\mathrm{RE}$, which was coupled with lower SCFA absorption capacity and higher concentrations of SCFA in the ruminal fluid. By contrast, no differences were observed in SCFA absorption rates and the expression of different genes related to SCFA absorption and intracellular $\mathrm{pH}$ regulation in the $\mathrm{RE}$ when the inherent acidosis index difference was narrow (Gao and Oba, 2016). Interestingly, abundance of $\mathrm{Na}^{+} / \mathrm{H}^{+}$-exchanger 3 in $\mathrm{RE}$ increased during SARA induction protocol over $5 \mathrm{~d}$, further suggesting that adaptation of transport function is a main mechanism for counteracting the development of SARA (Laarman et al., 2016).

\section{Epithelial Recovery Following SARA}

The current knowledge about the effects of high-grain feeding on the RE barrier and transport functions as described in the previous subsections has been modeled for a moderately severe case of acidosis in Figure 3A. This model also includes predictions for the recovery of $\mathrm{RE}$ functions following exposure to ruminal acidosis. The recovery of RE functions bears a higher degree of uncertainty because far fewer studies have been dedicated to the functional recovery of the RE after an acidotic insult. In the pioneering study of Gaebel and Martens (1988), where the isolated and washed reticulorumen of sheep was challenged with a $\mathrm{pH}$ of 4.8 in the presence of $85 \mathrm{mM}$ SCFA for $1 \mathrm{~h}$, absorption of $\mathrm{Na}^{+}$and $\mathrm{Cl}^{-}$was reduced acutely by more than $80 \%$ and required $5 \mathrm{~d}$ to return to the preacidosis values. Of note, the initial reaction upon return from acidotic to normal $\mathrm{pH}$ is a further increase in RE permeability (Penner et al., 2010; Meissner et al., 2017), and absorption of $\mathrm{Cl}^{-}$appeared to reach its nadir $1 \mathrm{~h}$ after ruminal $\mathrm{pH}$ was back to physiological values (Gaebel and Martens, 1988). The enhancement of RE permeability immediately following the acidotic insult may be explained by cell necrosis and the return of the swollen RE cells to normal cell volume, which further opens the paracellular space jointly with the damaged TJ.

The milder forms of SARA are not commonly associated with persistent increases in permeability or decreases in absorptive functions (Figure 3B). When $\mathrm{RE}$ of sheep that responded to an oral glucose challenge with developing SARA (153 min at $\mathrm{pH} 5.8$; nadir $\mathrm{pH}$ 5.36) were investigated immediately after the acidotic insult, no differences in acetate and butyrate uptake (Penner et al., 2009) and no difference in RE mannitol permeability (Penner et al., 2010) were noticed compared with water-drenched control sheep. In a recent study, Pederzolli et al. (2018) imposed a ruminal acidosis challenge by restricting calves to $25 \%$ of their voluntary DMI followed by the provision of $30 \%$ of the diet as pelleted barley grain. This protocol reduced $\mathrm{pH}$ in the rumen but also reduced $\mathrm{pH}$ in the large intestine (Gressley et al., 2011). Pederzolli et al. (2018) also reported that ruminal acidosis decreased the width of the ruminal papillae but that $1 \mathrm{~d}$ after the ruminal induction protocol, differences in permeability of the rumen, omasum, duodenum, jejunum, ileum, cecum, and proximal colon were not detectable. Interestingly, they reported that flux of mannitol and inulin tended to be reduced for calves exposed to acidosis relative to the control. The authors speculated that the lack of decreases in permeability shortly after the acidotic challenge may be attributed to increased expression for several of the TJ or TJ-associated proteins that were 

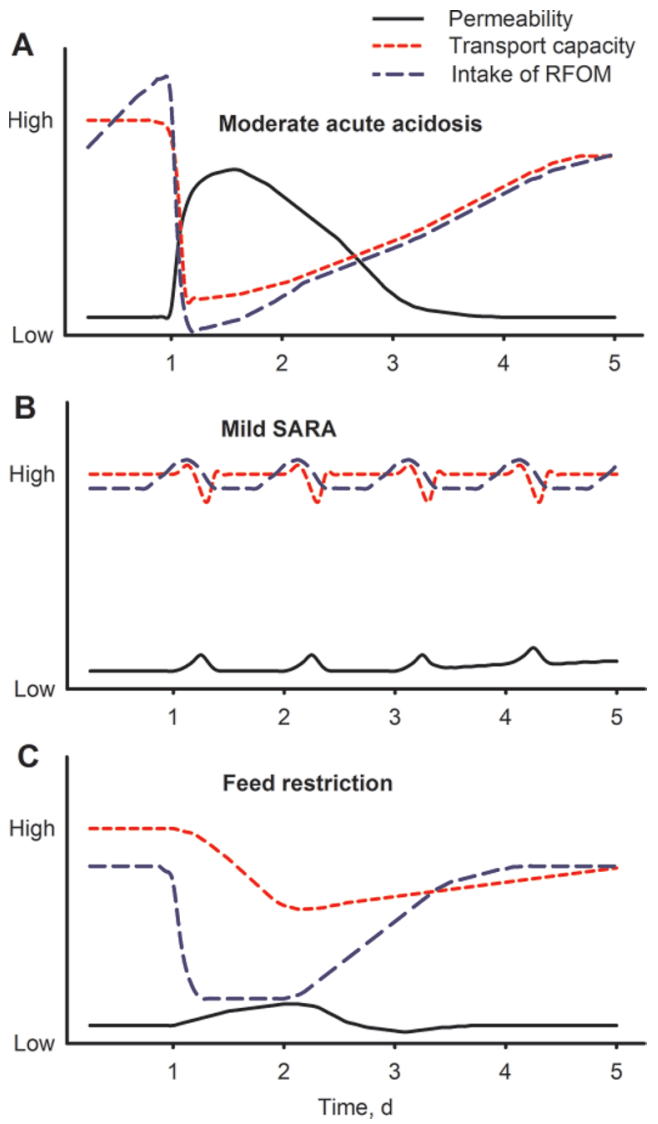

Figure 3. Models illustrating the relationship among the intake of rumen-fermentable OM (RFOM; especially rumen-fermentable starch), epithelial transport capacity, and epithelial barrier permeability during and after episodes of acidosis or feed restriction. Transport capacity refers to absorptive capacity for short-chain fatty acids and secretory capacity for ruminal buffers. Transport capacity has safety margins that ensure proper rumen functioning during unavoidable variations of $\mathrm{RFOM}$ intake. Ruminal acidosis occurs when RFOM intake exceeds the safety margins. (A) In the first example, the severity of acidosis is moderate and the animal is going off feed temporarily. The ruminal epithelium is damaged by the combined action of $\mathrm{pH}$ and short-chain fatty acid concentration and further by hyperosmolarity and inflammation. This leads to sharp decreases in transport function and increases in permeability. The latter continues when ruminal $\mathrm{pH}$ is already back to normal but has likely priority for restoration thereafter. Cows usually adapt their feed intake behavior to the slowly increasing transport capacity during the first week after a bout of acidosis. However, as transport function may not have fully recovered by then, overeating of RFOM and recurrent acidosis are possible at a later time (not shown in this graph). (B) The second example depicts "truly subacute" SARA resulting from gradual daily overeating of easily fermentable concentrates by a cow fed close to the limit of transport capacity. The mild barrier openings during the mild daily episodes of SARA, as well as the short impediments of transport function, are fully reversible upon return to physiological ruminal $\mathrm{pH}$ conditions. However, repeated entry of microbe-associated molecular patterns into the ruminal epithelium may induce focal inflammation that triggers gradual increases in ruminal permeability over time. (C) Feed restriction leads to gradual decreases in transport function and comparatively moderate increases in epithelial permeability. Upon refeeding, transport function recovers slowly and mostly does not keep pace with the rapidly recovering RFOM intake, thus making the cow susceptible to relative overeating and the development of ruminal acidosis. Epithelial barrier function is quickly restored after refeeding and may even overcompensate for a certain period after the feed restriction. evaluated. Thus, it is conceivable that adaptive mechanisms target to restore barrier function as quickly as possible after an acidotic insult. It may further appear that restoration of barrier function has priority over the restoration of absorptive functions; however, the latter is yet to be proven by suitable experiments.

\section{Systemic Inflammation During SARA}

Some of the early studies in acutely acidotic models suggested a role of systemic LPS endotoxins (Nagaraja et al., 1978) and inflammatory mediators (e.g., histamine; Irwin et al., 1979; Suber et al., 1979) in the pathophysiology and clinical signs of acidosis. Although it was initially thought that endotoxins and histamine act directly on peripheral organs to induce, for example, laminitis, it was later suggested that the primary site of action of LPS is the liver, which plays a key role in the development of systemic inflammation (Haubro Andersen and Jarløv, 1990). Meanwhile, it appears that systemic inflammation is present not only in acute acidosis but also during SARA. As such, acute-phase proteins [LPS-binding protein $(\mathbf{L B P})$, serum amyloid A, or haptoglobin] as surrogate markers of systemic inflammation have been suggested as possible diagnostic aids for SARA (Humer et al., 2018a; Zhao et al., 2018). However, systemic inflammatory responses may be partly blunted and highly variable in SARA. With the expectedly lower levels of LPS absorption during SARA, it is likely that many cows develop rapid LPS tolerance (Lehner and Hartung, 2002; Elsasser et al., 2005). On the other hand, it has been shown that some cattle have inherited hyperresponsiveness to repeated low-dose LPS infusion and may even respond with increasing TNF- $\alpha$ plasma concentrations after repeated LPS exposure (Elsasser et al., 2005). Other circumstances that may make inflammatory responses during SARA variable are concurrent illnesses. In the latter context, it has been shown that SARA aggravates responses to an intramammary LPS infusion such as decreased DMI, chewing activity, milk yield, and alterations of milk constituents (Aditya et al., 2017).

Another recent addition to our knowledge is that other regions of the GI tract, especially the large intestine, can also be involved in the systemic inflammatory response and should not be overlooked (Steele et al., 2016; Pederzolli et al., 2018). It has meanwhile become clear that grain overfeeding in the rumen can lead to increased bypass starch provision and fermentation in the hindgut, where hindgut acidosis may develop with similar negative consequences for hindgut epithelial functions and LPS absorption, as discussed in the previous sections for the RE (Gressley et al., 2011). 
The model depicted in Figure 1 suggests the cascade of events of inflammation during SARA. It proceeds from concurrent LPS release and the disruption of the $\mathrm{RE}$ barrier in response to feeding grain-rich diets. Once translocated into the portal circulation, LPS reaches the liver and is recognized by specific pattern recognition receptors of local immune cells, most importantly through the toll-like receptor 4 (TLR-4), which initiates powerful immune reactions (Plaizier et al., 2012; Zebeli and Metzler-Zebeli, 2012). Effective binding of LPS to TLR-4 is facilitated by the serum component LBP that complexes LPS and catalyzes its transfer to CD14 (membrane bound or soluble), which then associates with and activates TLR-4. Co-activation of myeloid differentiation-2 by the lipid A component of LPS potentiates the activation of macrophages (Kupffer cells in the liver; Beutler et al., 2003; Zebeli and Metzler-Zebeli, 2012). The host signaling molecules released by activated immune cells include proinflammatory mediators such as nitric oxide, prostaglandins, histamine, and cytokines as a hallmark of inflammation (Beutler et al., 2003). During acidosis, histamine may not only be released from immune cells but may also be absorbed from the rumen, considering that histamine may accumulate in the rumen at low $\mathrm{pH}$ (Ahrens, 1967; Irwin et al., 1979; Suber et al., 1979) and that low $\mathrm{pH}$ greatly promotes the ruminal absorption of intact histamine (Aschenbach and Gäbel, 2000; Aschenbach et al., 2000).

The downstream events of the TLR-4/myeloid differentiation- 2 receptor complex include the release of proinflammatory cytokines such as TNF- $\alpha$, IL-1, and IL-6, which use several adaptor molecules and lead to the activation of the central inflammatory transcription factor, NF-kB (Fitzgerald et al., 2003). The cytokines trigger the production of acute phase proteins (serum amyloid A, LBP, and haptoglobin), which occurs primarily in hepatocytes but also in other organs, including the gut (Ametaj et al., 2011). The majority of LPS taken up by Kupffer cells is subsequently subjected to detoxification by the liver and biliary excretion into the gut (Figure 1).

The cytokines released during inflammation are able to alter many organ functions because almost all cell types express cytokine receptors (Elsasser et al., 2008; Bradford et al., 2009). This may explain a pathophysiological link and the coincidence of SARA with other major diseases of cattle, such as displaced abomasum, laminitis, secondary ketosis, and liver diseases (Plaizier et al., 2008, 2012; Zebeli and Metzler-Zebeli, 2012). Furthermore, endotoxemia and inflammation may promote metabolic disturbances such as insulin resistance and oxidative stress and may promote catabolism and self-perpetuating immune-refractory states (Elsasser et al., 2008; Zebeli and Metzler-Zebeli, 2012; Bradford et al., 2015). These metabolic disturbances could increase the susceptibility to secondary infectious diseases of cattle (e.g., mastitis and metritis) and infertility (Zebeli and Metzler-Zebeli, 2012; Bradford et al., 2015). Indeed, poor metabolic health status and its associated lower performance and longevity are among the greatest challenges to the dairy industry at present.

\section{Diverse Faces of SARA}

The facts and conclusions described in the previous subsections represent an extracted picture from myriad data. However, there is variability in study outcomes that deserves some reflection here. In contrast to the highly reproducible models of acute acidosis that were mainly studied about $50 \mathrm{yr}$ ago, in which acidosis most reproducibly led to the death of animals if severe enough (Dunlop and Hammond, 1965; Juhász and Szegedi, 1968; Telle and Preston, 1971), studies on SARA have not consistently been eligible for simple and reproducible conclusions. For several aspects of diverse study outcomes, we refer readers to the recent review of Humer et al. (2018a), who analyzed the current challenges and controversies of SARA diagnosis. Apart from insufficiencies in diagnostic tools, which primarily relate to difficulties in correct ruminal $\mathrm{pH}$ assessment, study controversies originate from the multifaceted nature of SARA. The latter is partly based on individual differences in the susceptibility to SARA due to differences in DMI, chewing behavior, and ruminal motility and on many environmental, feed, and management factors that affect changes in blood, urine, and milk of SARA cows (Humer et al., 2018a). Individual variation in absorptive capacity for SCFA (Penner et al., 2009) and the $\mathrm{pH}$ regulatory capacity of the RE (Gao and Oba, 2016) as well as different tolerance toward a lowlevel LPS challenge (Elsasser et al., 2005) may further contribute to diverse outcomes of SARA challenges in different experimental settings and feeding situations, as discussed in previous subsections. Other limitations relate to the experimental settings themselves as reviewed previously by Nagaraja and Titgemeyer (2007). These limitations include inadequate replication, low intakes of the experimental diets, and individual feeding of cattle that limits the ability to extrapolate the data to cattle fed under industry standards. Also, different production and disease states of animals in production settings are often difficult to model in experimental studies (Nagaraja and Titgemeyer, 2007).

A core element in the definition of SARA is the gradual overfeeding with rumen-fermentable carbohydrates relative to the adaptation state of the animal and its ruminal microbiota (Kleen et al., 2003; Naga- 
raja and Titgemeyer, 2007). For most practical feeding situations, it follows that the occurrence of SARA can be deduced from the ratio between rumen-fermentable starch and physically effective NDF (Zebeli et al., 2012). However, such a generally valid concept has limitations in that excess intake of easily fermentable fiber such as alfalfa pellets may likewise induce SARA despite negligible provision of starch. The type of SARA induced by alfalfa pellet seems to be different from the type of SARA induced by grain because the former has been shown to exclude systemic inflammation (Khafipour et al., 2009b; Li et al., 2012). Furthermore, the replacement effects of sugar for starch are also incompletely understood. With pulse-dosing of larger amounts of sugar $(3 \mathrm{~kg})$, especially sucrose, ruminal $\mathrm{pH}$ depression was more severe than with pulse-dosing of comparable amounts of starch (Oba et al., 2015). By contrast, replacing starch with sucrose or lactose in TMR did not cause any depression in ruminal $\mathrm{pH}$ (Broderick et al., 2008; Chibisa et al., 2015) and was associated with positive production responses such as increased milk production (Broderick and Radloff, 2004) and increased milk fat yield (Broderick et al., 2008; Penner and Oba, 2009). Chibisa et al. (2015) attributed such positive effects of sugar-containing diets, at least in part, to adaptation events of the RE-namely, an increased $\mathrm{Cl}^{-}$-competitive absorption of acetate and propionate. This supports the general concept that the adaptation of the absorptive capacity for SCFA during adaptation to highly fermentable diets is a key event that decreases the susceptibility to SARA (Schwaiger et al., 2013; Qumar et al., 2016). It has further been demonstrated that such adaptation includes the enhancement of lactate absorption (Schwaiger et al., 2013; Qumar et al., 2016), which appears completely absent or negligible in roughage-fed ruminants (Qumar et al., 2016). Lactate is produced especially during sudden increases in easily fermentable carbohydrates with irregular feeding practices (Silberberg et al, 2013; Goto et al., 2016; Reis et al., 2018). Such irregular feeding practices are characterized by repeated bouts of mild acute (and partly lactic) acidosis that is different from "true" SARA caused by gradual daily overload with easily fermentable carbohydrates. Although both conditions are often summarized under the term SARA, the important difference is that the severity of acidosis may increase with each bout of mild acute acidosis (Dohme et al., 2008; Silberberg et al., 2013), partly due to persisting negative effects on RE transport and barrier functions (Figure 3A). By contrast, milder daily episodes of "truly subacute" SARA mostly imply an immediate and complete recovery of RE function between SARA episodes (Penner et al., 2010). Moreover, repeated true SARA often triggers adaptations of the $\mathrm{RE}$ and ruminal ecosystem that may lower the severity of acidosis with each bout. In a recent study by Nagata et al. (2018) applying 4 repeated periods of 7-d highgrain feeding interspersed by 7 -d periods of high-forage feeding, ruminal $\mathrm{pH}$ was close to the SARA threshold $(\mathrm{pH}<5.6$ for $>3$ h/d; Gozho et al., 2005) only during the first and second challenges but not during the third and fourth periods despite higher ruminal SCFA concentrations in the latter 2 periods (Nagata et al., 2018). This indicates that acid-base regulatory mechanisms of the RE (and possibly of saliva) adapted to effectively regulate ruminal $\mathrm{pH}$ despite a higher SCFA load. Nonetheless, over time, true SARA may also lead to persistent damage of the RE barrier due to focal inflammation induced by repeated bacterial or LPS entry into the RE because early inflammatory responses have been observed when ruminal $\mathrm{pH}$ is $<5.6$ for only $>1 \mathrm{~h}$ (Gozho et al., 2005; Figure 3B).

A newly emerging explanation for the variability in SARA readouts in different grain feeding situations and grain challenge models is the acknowledgment of hindgut acidosis when feeding high levels of rumen-resistant starch. A review by Steele et al. (2016) recently analyzed the similarities, diversities, and communication between the forestomach and the lower gut in different challenge situations, including the transition to highenergy diets. Their suggestion was that disruption of barrier function in the lower gut may promote systemic inflammation more intensely than disruption of the $\mathrm{RE}$ barrier. However, a main conclusion could be that decades of rumen-focused SARA research have dragged our attention away from the lower gut that is an integral part of the animal's GI tract and may suffer from severe acidosis that is missed by ruminal $\mathrm{pH}$ sensors and not amenable to supplementation of dietary buffers.

\section{CHALLENGES IMPOSED BY FEED RESTRICTION}

A second highly relevant challenge facing dairy cattle is a transient reduction in feed intake. Occurrences such as parturition (Hayirli et al., 2002), ruminal acidosis, heat stress (Rhoads et al., 2009), transportation events (González et al., 2012a,b), overstocking, and poor-quality feed or feeding management (Collings et al., 2011; Grant and Ferraretto, 2018) are causative factors for periods of low feed intake. Disease states such as hypocalcemia, ketosis, metritis, and mastitis may also reduce feed intake, imposing a secondary challenge. Previous studies have brought evidence that feed restriction has consequences for both transport and barrier functions of the RE. These changes are modeled in Figure 3C for 
a hypothetical feed restriction to approximately $25 \%$ of voluntary feed intake compared with the changes induced by a bout of acidosis.

Controlled studies that have evaluated low feed intake have demonstrated that exposure to low feed intake reduces SCFA absorption (Albornoz et al., 2013a) and does so in a dose-dependent manner (Zhang et al., 2013a): the greater the reduction in feed intake, the greater the reduction in SCFA absorption. Interestingly, the effect of low feed intake on SCFA absorption has been detected only in vivo (Albornoz et al., 2013a,b; Zhang et al., 2013a,b), suggesting that the reduction in absorptive surface area of the rumen and likely blood flow produces a pronounced effect that is not detectable ex vivo (Pederzolli et al., 2018). Low feed intake also increases permeability of the GI tract when exposed to severe reductions in feed intake $(25 \%$ of their voluntary DMI), with results detectable up to 3 wk after exposure to low feed intake (Zhang et al., 2013a,b).

Apparently, effects of low feed intake occur rapidly, as complete feed deprivation for $48 \mathrm{~h}$ reduced SCFA absorption by up to $60 \%$ (Gäbel et al., 1993) and increased permeability to 3-O-methyl- $\alpha$-D-glucose across the RE (Gäbel and Aschenbach, 2002). Other studies have reported that increased permeability can also be detected with measurements starting $48 \mathrm{~h}$ after the induction of low feed intake. However, those studies did not distinguish between the region of the GI tract involved (Zhang et al., 2013a,b). In contrast, Pederzolli et al. (2018) evaluated the effect of low feed intake on the regional permeability of the GI tract. In that study, DMI was restricted to $25 \%$ of voluntary intake over 4 $\mathrm{d}$, and animals were killed on the fifth day after full refeeding. The authors noted reductions in papillae surface area with low feed intake when measured $5 \mathrm{~d}$ after induction of the challenge, indicating that the RE was responding to reduced energy substrate availability. However, inulin permeability was not affected and mannitol permeability was reduced in the colon, and TJ and TJ-associated proteins were generally increased throughout the rumen, jejunum, and colon when comparing cattle exposed to low feed intake with the control cattle. The results of Pederzolli et al. (2018) and Zhang et al. (2013a,b) seem contradictory; however, it is plausible that initial exposure to low feed intake and the dramatic reduction in SCFA concentration in the rumen cause a lack of stimulatory signals promoting barrier function. With added time, the epithelia may adapt to restore barrier function properties to prevent long-term consequences that can arise with a leaky GI tract.

Finally, rapid dietary change can reduce barrier function. Wood et al. (2015) demonstrated an age-dependent improvement in total GI barrier function in calves as indicated by reduced urinary recovery of orally administered Cr-EDTA. However, imposing a 7-d weaning program compromised barrier function. Unfortunately, the authors of that study did not characterize TJ protein expression, leaving little opportunity to explain the mechanisms for the outcomes. However, considering that weaned calves have a dramatic increase in the quantity of starter consumed and a reduction in milk, it could be speculated that the weaning transition imposes both a challenge by luminal acidosis (increasing fermentation in the rumen but also intestinal regions) and a challenge by feed restriction as energy intake is often reduced. Moreover, the type of nutrient provision also changes during weaning, potentially leading to differences in concentrations of hormones that support GI barrier function (e.g., IGF-1 and glucagon-like peptide 2; Connor et al., 2010; Steele et al., 2012, 2016).

\section{ENERGETIC AND AA COSTS OF BARRIER FAILURE}

It is well acknowledged that low-grade systemic inflammation causes significant energetic costs. In dairy cows with graded induction of SARA, an increase in ruminal LPS concentration was associated with an acute phase response, indicating systemic inflammation. Ruminal LPS concentration correlated further with decreases in milk fat yield, FCM yield, and milk energy efficiency (Zebeli and Ametaj, 2009; Dong et al., 2011). This supports a role of systemic inflammation in those energetic losses and underlines their relevance to production based on a reduced mammary gland supply of milk precursors and altered mammary metabolism (Zebeli and Ametaj, 2009; Dong et al., 2011). The energetic costs of inflammation appear to be attributable primarily to a metabolic switch from energy-efficient oxidative phosphorylation to less efficient aerobic glycolytic energy production. Increased production of reactive oxygen species and lowered insulin sensitivity further promote energy wasting and lead to reduced cellular energy availability (Lacourt et al., 2018).

Although energy wasting during SARA appears obvious, surprisingly, very few studies have sought to evaluate the increased nutrient requirements associated directly with compromised barrier function of the GI tract, and none of them focused specifically on the RE barrier. It can be postulated that insults that compromise GI barrier function could induce energetic and AA costs that exceed those of other models of low-grade inflammation through reduced nutrient digestion, reduced absorption, increased cell maintenance and repair costs, and alterations of metabolism and nutrient partitioning to support the activation of an immune response. In a recent study, Kvidera et al. (2017a) used a model to purposely compromise barrier function of 
the GI tract using $\gamma$-secretase inhibitor relative to pairfed cattle. Use of the $\gamma$-secretase inhibitor increased respiration rate and heart rate and numerically increased free plasma LPS - all indicators of immune system activation. Although the $\gamma$-secretase inhibitor did not affect the yield of milk or milk components, insulin resistance developed as indicated by greater plasma insulin concentration without corresponding changes in plasma glucose, further suggesting immunoactivation and providing initial evidence of an energetic cost associated with barrier dysfunction leading to systemic immune activation.

Although only Kvidera et al. (2017a) have specifically addressed the contribution of barrier function in cattle, other models have addressed the nutrient cost of systemic inflammation. Presumably, these models have relevance to inflammation derived from the GI tract. Using an LPS infusion model coupled with a euglycemic clamp, Kvidera et al. (2017b) required infusion of $265 \mathrm{~g}$ of glucose/min to maintain plasma glucose concentration. When coupled with the reduction in glucose utilization for milk production, the authors estimated that more than $1.5 \mathrm{~kg}$ of glucose was used for immunoactivation in $12 \mathrm{~h}$, demonstrating a significant energetic cost. In another study, McNeil et al. (2016) sought to evaluate the AA cost of systemic immune activation. In that study, LPS was infused intravenously for $20 \mathrm{~h}$ and the authors noted a $30 \%$ reduction in plasma glucose, supporting the work of Kvidera et al. (2017b). Additionally, AA concentrations decreased by 20 to $50 \%$ with LPS infusion due to increasing hepatic uptake of AA, likely to support the acute phase protein response and possibly gluconeogenesis. Importantly, infusion of LPS markedly reduced concentration of glutamine, an important AA used as an energy source by the intestinal epithelia, providing some evidence for why systemic inflammation may specifically disturb GI functions, including GI barrier function.

\section{DAIRY FEEDING STRATEGIES TO SUPPORT THE EPITHELIAL BARRIER}

It is obvious that formulation of balanced and healthy diets that target a healthy rumen ecosystem is of great importance to provide tolerable proton, SCFA, and osmolyte concentrations and to curb E. coli proliferation, expression of virulence factor genes, and the release of endotoxin and other toxins in the rumen. Diets rich in readily fermentable carbohydrates and low in physically effective fiber can result in an increase in the abundance of pathogenic $E$. coli with virulence factors relevant to cell adhesion and biofilm formation in the rumen (Khafipour et al., 2011). General feeding recommendations and feed additives to mitigate the risk of
SARA in dairy cattle are given in a companion review of the authors (Humer et al., 2018b). In brief, and as a general rule, the feeding of high-producing cattle should aim at a balance between rumen-degradable starch in the diet and physically effective fiber. This balance is not easy to achieve because of the extremely high energetic needs of high-producing cattle. It requires optimum titration of rumen-degradable starches with bypass starch. Increasing the feeding frequency is one key measure for reducing the severity of SARA in lactating dairy cows (Macmillan et al., 2017). The use of feed additives that stimulate the rumen ecosystem and curb the release of toxic compounds in the rumen is also suggested. A large group of such additives belongs to the plant bioactive (phytogenic) compounds, some of them having direct or indirect effects on the GI barriers (Patra et al., 2018). As one example, a recent study by Kröger et al. (2017) observed that dietary supplementation of a commercial phytogenic blend product containing herbs, spices, and essential oils decreased the risk of SARA in cows fed $65 \%$ grain in the diet. This effect was associated with an improvement in rumination and ruminal ecosystem and decreases in biogenic amines in the ruminal fluid (Humer et al., 2018c). Other studies have supported an anti-inflammatory action of rumenavailable thiamine (Pan et al., 2017) and yeasts (Bach et al., 2018; Garcia Diaz et al., 2018; Humer et al., 2018c) in high-grain-challenged ruminants. Butyrate supplementation is used in weaning calves to support RE barrier development (Gorka et al., 2009; Kato et al., 2011; Górka et al., 2018). In the adult cow with a fully developed rumen, however, excess butyrate may promote the development of hyperkeratosis and parakeratosis, which increases the susceptibility of the RE to injury (Kauffold et al., 1977). Furthermore, the proportion of butyrate among the fermentation acids is already increased when feeding fiber-limited, starchrich diets (Loncke et al., 2009). As such, butyrate supplements currently do not appear to be appropriate supplements for RE barrier stabilization in dairy cows.

\section{CONCLUSIONS}

Gastrointestinal absorption and secretion across safeguarding barrier structures of the GI epithelia are vital for ensuring energy acquisition for life, and evolution has provided convenient safety margins for transport and barrier functions. However, the safety margins are challenged in high-producing dairy cows because their fermentative, transport, and barrier functions run close to their upper limits over extended periods. In such systems, it is essential to optimize adaptation to highly fermentable diets and to prevent any disturbances once the system has adapted to its maximum performance. 
The most relevant disturbances are bouts of acute or subacute acidosis and short periods of low feed intake, the latter frequently being followed by bouts of acidosis. A major part of the health and production consequences of such disturbances is attributable to impairment of GI barrier function, which, apart from interfering with nutrient acquisition directly, promotes the translocation of microbial toxins and MAMP, and possibly life microbiota, into the portal circulation. This leads to systemic inflammation with increased energetic costs and the promotion of numerous secondary diseases. The present review has clearly demonstrated that negative barrier effects in the RE play a key role in the health and production consequences of SARA and feed restriction. Given the long diffusion distances for acids across the multilayered structure of the RE, the dissipation of protons during acidosis is a challenge. Furthermore, the duration for full restoration of maximum RE function after SARA or feed restriction is perceivably longer in such complex epithelial structure than in a monolayer epithelium. We already have some knowledge on the factors and pathways that elicit damage to the RE barrier. By contrast, our knowledge on the mechanisms and kinetics of barrier restoration is still in its very early stages. Acquiring such knowledge will be a central task for future research. Moreover, a better discrimination between the contribution of disturbed barrier integrity among the rumen and other parts of the GI tract is also needed to better understand the systemic consequences of SARA and feed restriction and to finetune our feeding and management practice for avoidance of such consequences.

\section{ACKNOWLEDGMENTS}

JRA acknowledges a mobility grant from the Federal Office for Agriculture and Food (Bundesinstitut für Landwirtschaft und Ernährung, Bonn, Germany). GG received an Elsa Neumann stipend (state of Berlin, Germany), and AKP received a fellowship from the Alexander von Humboldt Foundation (Bonn, Germany).

\section{REFERENCES}

Aditya, S., E. Humer, P. Pourazad, R. Khiaosa-Ard, J. Huber, and Q. Zebeli. 2017. Intramammary infusion of Escherichia coli lipopolysaccharide negatively affects feed intake, chewing, and clinical variables, but some effects are stronger in cows experiencing subacute rumen acidosis. J. Dairy Sci. 100:1363-1377. https://doi .org/10.3168/jds.2016-11796.

Ahrens, F. A. 1967. Histamine, lactic acid, and hypertonicity as factors in the development of rumenitis in cattle. Am. J. Vet. Res. 28:1335-1342.

Albornoz, R. I., J. R. Aschenbach, D. R. Barreda, and G. B. Penner 2013a. Feed restriction reduces short-chain fatty acid absorption across the reticulo-rumen of beef cattle independent of diet. J. Anim. Sci. 91:4730-4738. https://doi.org/10.2527/jas.2012-6223.
Albornoz, R. I., J. R. Aschenbach, D. R. Barreda, and G. B. Penner. 2013b. Moderate decreases in the forage-to-concentrate ratio prior to feed restriction and increases thereafter independently improve the recovery from a feed restriction insult in beef cattle. J. Anim. Sci. 91:4739-4749.

Allen, M. S. 1997. Relationship between fermentation acid production in the rumen and the requirement for physically effective fiber. J. Dairy Sci. 80:1447-1462. https://doi.org/10.3168/jds.S0022 -0302(97)76074-0.

Ametaj, B. N., A. Hosseini, J. F. Odhiambo, S. Iqbal, S. Sharma Q. Deng, T. H. Lam, U. Farooq, Q. Zebeli, and S. M. Dunn. 2011. Application of acute phase proteins for monitoring inflammatory states in cattle. Accessed Month Sep. 2018. http://www .intechopen.com/articles/show/title/application-of-acute-phase -proteins-for-monitoring-inflammatory-states-in-cattle.

Ametaj, B. N., Q. Zebeli, F. Saleem, M. J. Lewis, N. Psychogios, J. Xia, S. M. Dunn, and D. S. Wishart. 2010. Metabolomics reveals unhealthy alterations in rumen metabolism with increased proportion of cereal grain in the diet of dairy cows. Metabolomics 6:583-594.

Aschenbach, J. R., S. Bilk, G. Tadesse, F. Stumpff, and G. Gäbel. 2009. Bicarbonate-dependent and bicarbonate-independent mechanisms contribute to nondiffusive uptake of acetate in the ruminal epithelium of sheep. Am. J. Physiol. Gastrointest. Liver Physiol. 296:G1098-G1107. https://doi.org/10.1152/ajpgi.90442.2008.

Aschenbach, J. R., B. Fürll, and G. Gäbel. 1998. Histamine affects growth of sheep ruminal epithelial cells kept in primary culture. Zentralbl. Veterinarmed. A 45:411-416.

Aschenbach, J. R., and G. Gäbel. 2000. Effect and absorption of histamine in sheep rumen: Significance of acidotic epithelial damage. J. Anim. Sci. 78:464-470.

Aschenbach, J. R., N. B. Kristensen, S. S. Donkin, H. M. Hammon, and G. B. Penner. 2010. Gluconeogenesis in dairy cows: The secret of making sweet milk from sour dough. IUBMB Life 62:869-877. https://doi.org/10.1002/iub.400.

Aschenbach, J. R., R. Oswald, and G. Gäbel. 2000. Transport, catabolism, and release of histamine in the ruminal epithelium of sheep. Pflugers Arch. 440:171-178.

Aschenbach, J. R., G. B. Penner, F. Stumpff, and G. Gäbel. 2011. Ruminant Nutrition Symposium: Role of fermentation acid absorption in the regulation of ruminal pH. J. Anim. Sci. 89:1092-1107. https://doi.org/10.2527/jas.2010-3301.

Bach, A., I. Guasch, G. Elcoso, F. Chaucheyras-Durand, M. Castex, F. Fàbregas, E. Garcia-Fruitos, and A. Aris. 2018. Changes in gene expression in the rumen and colon epithelia during the dry period through lactation of dairy cows and effects of live yeast supplementation. J. Dairy Sci. 101:2631-2640. https://doi.org/10 $.3168 /$ jds.2017-13212.

Bäsler, K., S. Bergmann, M. Heisig, A. Naegel, M. Zorn-Kruppa, and J. M. Brandner. 2016. The role of tight junctions in skin barrier function and dermal absorption. J. Control. Release 242:105-118. https://doi.org/10.1016/j.jconrel.2016.08.007.

Beutler, B., K. Hoebe, X. Du, and R. J. Ulevitch. 2003. How we detect microbes and respond to them: The Toll-like receptors and their transducers. J. Leukoc. Biol. 74:479-485.

Bondzio, A., C. Gabler, B. Badewien-Rentzsch, P. Schulze, H. Martens, and R. Einspanier. 2011. Identification of differentially expressed proteins in ruminal epithelium in response to a concentratesupplemented diet. Am. J. Physiol. Gastrointest. Liver Physiol. 301:G260-G268. https://doi.org/10.1152/ajpgi.00304.2010.

Bradford, B. J., L. K. Mamedova, J. E. Minton, J. S. Drouillard, and B. J. Johnson. 2009. Daily injection of tumor necrosis factor-alpha increases hepatic triglycerides and alters transcript abundance of metabolic genes in lactating dairy cattle. J. Nutr. 139:1451-1456.

Bradford, B. J., K. Yuan, J. K. Farney, L. K. Mamedova, and A. J. Carpenter. 2015. Invited review: Inflammation during the transition to lactation: New adventures with an old flame. J. Dairy Sci. 98:6631-6650. https://doi.org/10.3168/jds.2015-9683.

Broderick, G. A., N. D. Luchini, S. M. Reynal, G. A. Varga, and V. A. Ishler. 2008. Effect on production of replacing dietary starch with 
sucrose in lactating dairy cows. J. Dairy Sci. 91:4801-4810. https: //doi.org/10.3168/jds.2008-1480.

Broderick, G. A., and W. J. Radloff. 2004. Effect of molasses supplementation on the production of lactating dairy cows fed diets based on alfalfa and corn silage. J. Dairy Sci. 87:2997-3009. https: //doi.org/10.3168/jds.S0022-0302(04)73431-1.

Bugaut, M. 1987. Occurrence, absorption and metabolism of short chain fatty acids in the digestive tract of mammals. Comp. Biochem. Physiol. B 86:439-472.

Chibisa, G. E., P. Gorka, G. B. Penner, R. Berthiaume, and T. Mutsvangwa. 2015. Effects of partial replacement of dietary starch from barley or corn with lactose on ruminal function, short-chain fatty acid absorption, nitrogen utilization, and production performance of dairy cows. J. Dairy Sci. 98:2627-2640. https://doi.org/ $10.3168 /$ jds.2014-8827.

Collings, L. K., D. M. Weary, N. Chapinal, and M. A. von Keyserlingk. 2011. Temporal feed restriction and overstocking increase competition for feed by dairy cattle. J. Dairy Sci. 94:5480-5486. https:// doi.org/10.3168/jds.2011-4370.

Connor, E. E., R. L. Baldwin 6th, A. V. Capuco, C. M. Evock-Clover, S. E. Ellis, and K. S. Sciabica. 2010. Characterization of glucagonlike peptide 2 pathway member expression in bovine gastrointestinal tract. J. Dairy Sci. 93:5167-5178. https://doi.org/10.3168/ jds.2010-3205.

Desnoyers, M., S. Giger-Reverdin, C. Duvaux-Ponter, and D. Sauvant 2009. Modeling of off-feed periods caused by subacute acidosis in intensive lactating ruminants: Application to goats. J. Dairy Sci. 92:3894-3906. https://doi.org/10.3168/jds.2008-1784.

Dijkstra, J., H. Boer, J. Van Bruchem, M. Bruining, and S. Tamminga. 1993. Absorption of volatile fatty acids from the rumen of lactating dairy cows as influenced by volatile fatty acid concentration, $\mathrm{pH}$ and rumen liquid volume. Br. J. Nutr. 69:385-396.

Dijkstra, J., J. L. Ellis, E. Kebreab, A. B. Strathe, S. López, J. France, and A. Bannink. 2012. Ruminal pH regulation and nutritional consequences of low pH. Anim. Feed Sci. Technol. 172:22-33. https:// doi.org/10.1016/j.anifeedsci.2011.12.005.

Dohme, F., T. J. DeVries, and K. A. Beauchemin. 2008. Repeated ruminal acidosis challenges in lactating dairy cows at high and low risk for developing acidosis: Ruminal pH. J. Dairy Sci. 91:35543567. https://doi.org/10.3168/jds.2008-1264.

Dong, G., S. Liu, Y. Wu, C. Lei, J. Zhou, and S. Zhang. 2011. Dietinduced bacterial immunogens in the gastrointestinal tract of dairy cows: Impacts on immunity and metabolism. Acta Vet. Scand. 53:48. https://doi.org/10.1186/1751-0147-53-48.

Dua, K., S. Leonhard, H. Martens, S. K. Abbas, and A. D. Care. 1994 Effects of parathyroid hormone and parathyroid hormone-related protein on the rates of absorption of magnesium, calcium, sodium, potassium and phosphate ions from the reticulo-rumen of sheep. Exp. Physiol. 79:401-408.

Dunlop, R. H., and P. B. Hammond. 1965. D-lactic acidosis of ruminants. Ann. N. Y. Acad. Sci. 119:1109-1132.

Eckhart, L., S. Lippens, E. Tschachler, and W. Declercq. 2013. Cell death by cornification. Biochim. Biophys. Acta 1833:3471-3480. https://doi.org/10.1016/j.bbamcr.2013.06.010.

Elsasser, T. H., J. W. Blum, and S. Kahl. 2005. Characterization of calves exhibiting a novel inheritable TNF-alpha hyperresponsiveness to endotoxin: Associations with increased pathophysiological complications. J. Appl. Physiol. 98:2045-2055. https://doi.org/10 .1152/japplphysiol.01050.2004.

Elsasser, T. H., T. J. Caperna, C.-J. Li, S. Kahl, and J. L. Sartin. 2008. Critical control points in the impact of the proinflammatory immune response on growth and metabolism. J. Anim. Sci. 86:E105-E125.

Fitzgerald, K. A., D. C. Rowe, B. J. Barnes, D. R. Caffrey, A. Visintin, E. Latz, B. Monks, P. M. Pitha, and D. T. Golenbock. 2003 LPS-TLR4 signaling to IRF-3/7 and NF-kappaB involves the toll adapters TRAM and TRIF. J. Exp. Med. 198:1043-1055.

Gäbel, G., and J. R. Aschenbach. 2002. Influence of food deprivation on the transport of 3-O-methyl-alpha-D-glucose across the isolated ruminal epithelium of sheep. J. Anim. Sci. 80:2740-2746.
Gäbel, G., J. R. Aschenbach, and F. Müller. 2002. Transfer of energy substrates across the ruminal epithelium: Implications and limitations. Anim. Health Res. Rev. 3:15-30.

Gäbel, G., M. Marek, and H. Martens. 1993. Influence of food deprivation on SCFA and electrolyte transport across sheep reticulorumen. Zentralbl. Veterinarmed. A 40:339-344.

Gäbel, G., S. Vogler, and H. Martens. 1991. Short-chain fatty acids and $\mathrm{CO}_{2}$ as regulators of $\mathrm{Na}^{+}$and $\mathrm{Cl}^{-}$absorption in isolated sheep rumen mucosa. J. Comp. Physiol. B 161:419-426.

Gaebel, G., M. Bell, and H. Martens. 1989. The effect of low mucosal $\mathrm{pH}$ on sodium and chloride movement across the isolated rumen mucosa of sheep. Q. J. Exp. Physiol. 74:35-44.

Gaebel, G., and H. Martens. 1988. Reversibility of acid induced changes in absorptive function of sheep rumen. Zentralbl. Veterinarmed. A 35:157-160.

Gaebel, G., H. Martens, M. Suendermann, and P. Galfi. 1987. The effect of diet, intraruminal $\mathrm{pH}$ and osmolarity on sodium, chloride and magnesium absorption from the temporarily isolated and washed reticulo-rumen of sheep. Q. J. Exp. Physiol. 72:501-511.

Gao, X., and M. Oba. 2016. Characteristics of dairy cows with a greater or lower risk of subacute ruminal acidosis: Volatile fatty acid absorption, rumen digestion, and expression of genes in rumen epithelial cells. J. Dairy Sci. 99:8733-8745. https://doi.org/10.3168/ jds.2016-11570.

Garcia, M., B. J. Bradford, and T. G. Nagaraja. 2017. Invited review: Ruminal microbes, microbial products, and systemic inflammation. Prof. Anim. Sci. 33:635-650. https://doi.org/10.15232/pas .2017-01663.

Garcia Diaz, T., A. Ferriani Branco, F. A. Jacovaci, C. Cabreira Jobim, D. C. Bolson, and J. L. Pratti Daniel. 2018. Inclusion of live yeast and mannan-oligosaccharides in high grain-based diets for sheep: Ruminal parameters, inflammatory response and rumen morphology. PLoS One 13:e0193313. https://doi.org/10.1371/ journal.pone.0193313.

Gemmell, R. T. 1973. Langerhans cells in the ruminal epithelium of the sheep. J. Ultrastruct. Res. 43:256-259.

Glover, L. E., J. S. Lee, and S. P. Colgan. 2016. Oxygen metabolism and barrier regulation in the intestinal mucosa. J. Clin. Invest. 126:3680-3688. https://doi.org/10.1172/JCI84429.

González, L. A., K. S. Schwartzkopf-Genswein, M. Bryan, R. Silasi, and F. Brown. 2012a. Factors affecting body weight loss during commercial long haul transport of cattle in North America. J. Anim. Sci. 90:3630-3639. https://doi.org/10.2527/jas.2011-4786.

González, L. A., K. S. Schwartzkopf-Genswein, M. Bryan, R. Silasi, and F. Brown. 2012b. Relationships between transport conditions and welfare outcomes during commercial long haul transport of cattle in North America. J. Anim. Sci. 90:3640-3651. https://doi .org/10.2527/jas.2011-4796.

Gorka, P., Z. M. Kowalski, P. Pietrzak, A. Kotunia, R. Kiljanczyk, J. Flaga, J. J. Holst, P. Guilloteau, and R. Zabielski. 2009. Effect of sodium butyrate supplementation in milk replacer and starter diet on rumen development in calves. J. Physiol. Pharmacol. 60(Suppl. $3): 47-53$

Górka, P., Z. M. Kowalski, R. Zabielski, and P. Guilloteau. 2018. Invited review: Use of butyrate to promote gastrointestinal tract development in calves. J. Dairy Sci. 101:4785-4800. https://doi .org/10.3168/jds.2017-14086.

Goto, H., A. Q. Qadis, Y. H. Kim, K. Ikuta, T. Ichijo, and S. Sato. 2016. Effects of a bacterial probiotic on ruminal $\mathrm{pH}$ and volatile fatty acids during subacute ruminal acidosis (SARA) in cattle. J. Vet. Med. Sci. 78:1595-1600. https://doi.org/10.1292/jvms.16 $-0211$.

Gozho, G. N., J. C. Plaizier, D. O. Krause, A. D. Kennedy, and K. M. Wittenberg. 2005. Subacute ruminal acidosis induces ruminal lipopolysaccharide endotoxin release and triggers an inflammatory response. J. Dairy Sci. 88:1399-1403. https://doi.org/10.3168/jds .S0022-0302(05)72807-1.

Graham, C., and N. L. Simmons. 2005. Functional organization of the bovine rumen epithelium. Am. J. Physiol. Regul. Integr. Comp. Physiol. 288:R173-R181 
Grant, R. J., and L. F. Ferraretto. 2018. Silage review: Silage feeding management: Silage characteristics and dairy cow feeding behavior. J. Dairy Sci. 101:4111-4121. https://doi.org/10.3168/jds.2017 -13729 .

Greco, G., F. Hagen, S. Meißner, Z. Shen, Z. Lu, S. Amasheh, and J. R. Aschenbach. 2018. Effect of individual SCFA on the epithelial barrier of sheep rumen under physiological and acidotic luminal pH conditions. J. Anim. Sci. 96:126-142. https://doi.org/10.1093/ jas/skx017.

Gressley, T. F., M. B. Hall, and L. E. Armentano. 2011. Ruminant nutrition symposium: Productivity, digestion, and health responses to hindgut acidosis in ruminants. J. Anim. Sci. 89:1120-1130. https://doi.org/10.2527/jas.2010-3460.

Haubro Andersen, P., and N. Jarløv. 1990. Investigation of the possible role of endotoxin, TXA2, PGI2 and PGE2 in experimentally induced rumen acidosis in cattle. Acta Vet. Scand. 31:27-38.

Hayirli, A., R. R. Grummer, E. V. Nordheim, and P. M. Crump. 2002. Animal and dietary factors affecting feed intake during the prefresh transition period in Holsteins. J. Dairy Sci. 85:3430-3443. https://doi.org/10.3168/jds.S0022-0302(02)74431-7.

Henrikson, R. C., and B. D. Stacy. 1971. The barrier to diffusion across ruminal epithelium: A study by electron microscopy using horseradish peroxidase, lanthanum, and ferritin. J. Ultrastruct. Res. 34:72-82.

Hernández, J., J. L. Benedito, A. Abuelo, and C. Castillo. 2014. Ruminal acidosis in feedlot: From aetiology to prevention. Sci. World J. 2014:702572. https://doi.org/10.1155/2014/702572.

Hoffmann, R. R., and B. Schnorr. 1982. Die Funktionelle Morphologie des Wiederkäuermagens. Enke, Stuttgart, Germany.

Hollmann, M., I. Miller, K. Hummel, S. Sabitzer, B. U. Metzler-Zebeli, E. Razzazi-Fazeli, and Q. Zebeli. 2013. Downregulation of cellular protective factors of rumen epithelium in goats fed high energy diet. PLoS One 8:e81602. https://doi.org/10.1371/journal.pone .0081602 .

Hua, C., J. Tian, P. Tian, R. Cong, Y. Luo, Y. Geng, S. Tao, Y. Ni, and R. Zhao. 2017. Feeding a high concentration diet induces unhealthy alterations in the composition and metabolism of ruminal microbiota and host response in a goat model. Front. Microbiol. 8:138. https://doi.org/10.3389/fmicb.2017.00138.

Humer, E., J. R. Aschenbach, V. Neubauer, I. Kröger, R. Khiaosaard, W. Baumgartner, and Q. Zebeli. 2018a. Signals for identifying cows at risk of subacute ruminal acidosis in dairy veterinary practice. J. Anim. Physiol. Anim. Nutr. (Berl.) 102:380-392. https: //doi.org/10.1111/jpn.12850.

Humer, E., I. Kröger, V. Neubauer, N. Reisinger, K. Schedle, and Q. Zebeli. 2018c. Supplementing phytogenic compounds or autolyzed yeast modulates ruminal biogenic amines and plasma metabolome in dry cows experiencing subacute ruminal acidosis. J. Dairy Sci. 101:9559-9574.

Humer, E., R. M. Petri, J. R. Aschenbach, B. J. Bradford, G. B Penner, M. Tafaj, K. H. Südekum, and Q. Zebeli. 2018b. Invited review: Practical feeding management recommendations to mitigate the risk of subacute ruminal acidosis in dairy cattle. J. Dairy Sci. 101:872-888. https://doi.org/10.3168/jds.2017-13191.

Hurley, J. C. 1995. Endotoxemia: Methods of detection and clinical correlates. Clin. Microbiol. Rev. 8:268-292.

Irwin, L. N., G. E. Mitchell Jr., R. E. Tucker, and G. T. Schelling. 1979. Histamine, tyramine, tryptamine and electrolytes during glucose induced lactic acidosis. J. Anim. Sci. 48:367-374.

Jørgensen, C. H., R. Spörndly, J. Bertilsson, and S. Østergaard. 2016. Invited review: Carryover effects of early lactation feeding on total lactation performance in dairy cows. J. Dairy Sci. 99:3241-3249. https://doi.org/10.3168/jds.2014-9043.

Juhász, B., and B. Szegedi. 1968. Studies on the etiology of rumen acidosis in ruminants. Arch. Exp. Veterinarmed. 22:969-993.

Kato, S., K. Sato, H. Chida, S. G. Roh, S. Ohwada, S. Sato, P. Guilloteau, and K. Katoh. 2011. Effects of Na-butyrate supplementation in milk formula on plasma concentrations of GH and insulin, and on rumen papilla development in calves. J. Endocrinol. 211:241248. https://doi.org/10.1530/JOE-11-0299.
Kauffold, P., J. Voigt, and G. Herrendörfer. 1977. The effect of nutritional factors on the ruminal mucosa. 3. Condition of the mucosa after infusion of propionic acid, acetic acid and butyric acid. Arch. Tierernahr. 27:201-211.

Khafipour, E., D. Krause, and J. C. Plaizier. 2009a. A grain-based subacute ruminal acidosis challenge causes translocation of lipopolysaccharide and triggers inflammation. J. Dairy Sci. 92:1060-1070.

Khafipour, E., D. O. Krause, and J. C. Plaizier. 2009b. Alfalfa pelletinduced subacute ruminal acidosis in dairy cows increases bacterial endotoxin in the rumen without causing inflammation. J. Dairy Sci. 92:1712-1724.

Khafipour, E., J. C. Plaizier, P. C. Aikman, and D. O. Krause. 2011. Population structure of rumen Escherichia coli associated with subacute ruminal acidosis (SARA) in dairy cattle. J. Dairy Sci. 94:351-360. https://doi.org/10.3168/jds.2010-3435.

Kleen, J. L., G. A. Hooijer, J. Rehage, and J. P. Noordhuizen. 2003. Subacute ruminal acidosis (SARA): A review. J. Vet. Med. A Physiol. Pathol. Clin. Med. 50:406-414.

Klevenhusen, F., M. Hollmann, L. Podstatzky-Lichtenstein, R. Krametter-Frötscher, J. R. Aschenbach, and Q. Zebeli. 2013. Feeding barley grain-rich diets altered electrophysiological properties and permeability of the ruminal wall in a goat model. J. Dairy Sci. 96:2293-2302. https://doi.org/10.3168/jds.2012-6187.

Kröger, I., E. Humer, V. Neubauer, N. Reisinger, S. Adytia, and Q. Zebeli. 2017. Modulation of chewing behavior and reticular $\mathrm{pH}$ in non-lactating cows challenged with concentrate-rich diets supplemented with phytogenic compounds and autolyzed yeast. J. Dairy Sci. 100:9702-9714. https://doi.org/10.3168/jds.2017-12755.

Kunzmann, P. 2018. Nutztiere richtig nutzen: Ethik und Ökonomie bei der Tierzucht. Pages 107-109 in LBH: 9. Leipziger Tierärztekongress-Tagungsband 3. R. Rackwitz, M. Pees, J. R. Aschenbach, and G. Gäbel, ed. Veterinärmedizinische Fakultät der Universität Leipzig, Leipzig, Germany.

Kvidera, S. K., M. J. Dickson, A. Abuajamieh, D. B. Snider, M. V Sanz Fernandez, J. S. Johnson, A. F. Keating, P. J. Gorden, H. B. Green, K. M. Schoenberg, and L. H. Baumgard. 2017a. Intentionally induced intestinal barrier dysfunction causes inflammation, affects metabolism, and reduces productivity in lactating Holstein cows. J. Dairy Sci. 100:4113-4127. https://doi.org/10.3168/jds .2016-12349.

Kvidera, S. K., E. A. Horst, A. Abuajamieh, E. J. Mayorga, M. V. Sanz Fernandez, and L. H. Baumgard. 2017b. Glucose requirements of an activated immune system in lactating Holstein cows. J. Dairy Sci. 100:2360-2374. https://doi.org/10.3168/jds.2016 $-12001$.

Laarman, A. H., R. A. Pederzolli, K. M. Wood, G. B. Penner, and B. W. McBride. 2016. Effects of subacute ruminal acidosis and low feed intake on short-chain fatty acid transporters and flux pathways in Holstein steers. J. Anim. Sci. 94:3729-3737. https://doi .org/10.2527/jas.2016-0638.

Lacourt, T. E., E. G. Vichaya, G. S. Chiu, R. Dantzer, and C. J. Heijnen. 2018. The high costs of low-grade inflammation: Persistent fatigue as a consequence of reduced cellular-energy availability and non-adaptive energy expenditure. Front. Behav. Neurosci. 12:78. https://doi.org/10.3389/fnbeh.2018.00078.

Lavker, R. M., and A. G. Matoltsy. 1970. Formation of horny cells: The fate of cell organelles and differentiation products in ruminal epithelium. J. Cell Biol. 44:501-512.

Lehner, M. D., and T. Hartung. 2002. Endotoxin tolerance-mechanisms and beneficial effects in bacterial infection. Rev. Physiol Biochem. Pharmacol. 144:95-141.

Li, S., E. Khafipour, D. O. Krause, A. Kroeker, J. C. RodriguezLecompte, G. N. Gozho, and J. C. Plaizier. 2012. Effects of subacute ruminal acidosis challenges on fermentation and endotoxins in the rumen and hindgut of dairy cows. J. Dairy Sci. 95:294-303. https://doi.org/10.3168/jds.2011-4447.

Liu, J. H., T. T. Xu, Y. J. Liu, W. Y. Zhu, and S. Y. Mao. 2013. A high-grain diet causes massive disruption of ruminal epithelial tight junctions in goats. Am. J. Physiol. Regul. Integr. Comp. Physiol. 305:R232-R241. https://doi.org/10.1152/ajpregu.00068 .2013 . 
Lodemann, U., and H. Martens. 2006. Effects of diet and osmotic pressure on $\mathrm{Na}^{+}$transport and tissue conductance of sheep isolated rumen epithelium. Exp. Physiol. 91:539-550.

Loncke, C., I. Ortigues-Marty, J. Vernet, H. Lapierre, D. Sauvant, and P. Nozière. 2009. Empirical prediction of net portal appearance of volatile fatty acids, glucose, and their secondary metabolites (beta-hydroxybutyrate, lactate) from dietary characteristics in ruminants: A meta-analysis approach. J. Anim. Sci. 87:253-268. https://doi.org/10.2527/jas.2008-0939.

Macmillan, K., X. Gao, and M. Oba. 2017. Increased feeding frequency increased milk fat yield and may reduce the severity of subacute ruminal acidosis in higher-risk cows. J. Dairy Sci. 100:1045-1054. https://doi.org/10.3168/jds.2016-11337.

Malago, J. J. 2015. Contribution of microbiota to the intestinal physicochemical barrier. Benef. Microbes 6:295-311. https://doi.org/10 .3920/BM2014.0041.

Markov, A. G., J. R. Aschenbach, and S. Amasheh. 2015. Claudin clusters as determinants of epithelial barrier function. IUBMB Life 67:29-35. https://doi.org/10.1002/iub.1347.

Martens, H. S. Leonhard-Marek, M. Röntgen, and F. Stumpff. 2018. Magnesium homeostasis in cattle: Absorption and excretion. Nutr. Res. Rev. 31:114-130. https://doi.org/10.1017/ S0954422417000257.

Martín-Tereso, J., and H. Martens. 2014. Calcium and magnesium physiology and nutrition in relation to the prevention of milk fever and tetany (dietary management of macrominerals in preventing disease). Vet. Clin. North Am. Food Anim. Pract. 30:643-670. https://doi.org/10.1016/j.cvfa.2014.07.007.

McNeil, C. J., S. O. Hoskin, D. M. Bremner, G. Holtrop, and G. E. Lobley. 2016. Whole-body and splanchnic amino acid metabolism in sheep during an acute endotoxin challenge. Br. J. Nutr. 116:211-222. https://doi.org/10.1017/S0007114516001860.

Meissner, S., F. Hagen, C. Deiner, D. Günzel, G. Greco, Z. Shen, and J. R. Aschenbach. 2017. Key role of short chain fatty acids in epithelial barrier failure during ruminal acidosis. J. Dairy Sci. 100:6662-6675. https://doi.org/10.3168/jds.2016-12262.

Minuti, A., S. Ahmed, E. Trevisi, F. Piccioli-Cappelli, G. Bertoni, N. Jahan, and P. Bani. 2014. Experimental acute rumen acidosis in sheep: Consequences on clinical, rumen, and gastrointestinal permeability conditions and blood chemistry. J. Anim. Sci. 92:39663977. https://doi.org/10.2527/jas.2014-7594.

Müller, F., J. R. Aschenbach, and G. Gäbel. 2000. Role of $\mathrm{Na}^{+} / \mathrm{H}^{+}$ exchange and $\mathrm{HCO}_{3}{ }^{-}$transport in $\mathrm{pH}_{\mathrm{i}}$ recovery from intracellular acid load in cultured epithelial cells of sheep rumen. J. Comp. Physiol. B 170:337-343.

Nagaraja, T. G., L. R. Fina, E. E. Bartley, and H. D. Anthony. 1978. Endotoxic activity of cell-free rumen fluid from cattle fed hay or grain. Can. J. Microbiol. 24:1253-1261.

Nagaraja, T. G., and E. C. Titgemeyer. 2007. Ruminal acidosis in beef cattle: The current microbiological and nutritional outlook. J. Dairy Sci. 90(Suppl. 1):E17-E38. https://doi.org/10.3168/jds .2006-478.

Nagata, R., Y. H. Kim, A. Ohkubo, S. Kushibiki, T. Ichijo, and S. Sato. 2018. Effects of repeated subacute ruminal acidosis challenges on the adaptation of the rumen bacterial community in Holstein bulls. J. Dairy Sci. 101:4424-4436. https://doi.org/10.3168/ jds.2017-13859.

Oba, M., J. L. Mewis, and Z. Zhining. 2015. Effects of ruminal doses of sucrose, lactose, and corn starch on ruminal fermentation and expression of genes in ruminal epithelial cells. J. Dairy Sci. 98:586594. https://doi.org/10.3168/jds.2014-8697.

Owens, F. N., D. S. Secrist, W. J. Hill, and D. R. Gill. 1998. Acidosis in cattle: A review. J. Anim. Sci. 76:275-286.

Pan, X. H., L. Yang, Y. Beckers, F. G. Xue, Z. W. Tang, L. S. Jiang, and B. H. Xiong. 2017. Thiamine supplementation facilitates thiamine transporter expression in the rumen epithelium and attenuates high-grain-induced inflammation in low-yielding dairy cows. J. Dairy Sci. 100:5329-5342. https://doi.org/10.3168/jds.2016 $-11966$.

Patra, A. K., S. Amasheh, and J. R. Aschenbach. 2018. Modulation of gastrointestinal barrier and nutrient transport function in farm animals by natural plant bioactive compounds - A comprehensive review. Crit. Rev. Food Sci. Nutr. https://doi.org/10.1080/ 10408398.2018.1486284.

Pederzolli, R. A., A. G. Van Kessel, J. Campbell, S. Hendrick, K. M. Wood, and G. B. Penner. 2018. Effect of ruminal acidosis and short-term low feed intake on indicators of gastrointestinal barrier function in Holstein steers. J. Anim. Sci. 96:108-125. https://doi .org/10.1093/jas/skx049.

Penner, G. B., J. R. Aschenbach, G. Gäbel, R. Rackwitz, and M. Oba. 2009. Epithelial capacity for apical uptake of short chain fatty acids is a key determinant for intraruminal $\mathrm{pH}$ and the susceptibility to sub-acute ruminal acidosis in sheep. J. Nutr. 139:1714-1720.

Penner, G. B., J. R. Aschenbach, K. Wood, M. E. Walpole, R. Kanafany-Guzman, S. Hendrick, and J. Campbell. 2014. Characterizing barrier function among regions of the gastrointestinal tract in Holstein steers. Anim. Prod. Sci. 54:1282-1287. https://doi.org/10 .1071/AN14285.

Penner, G. B., and M. Oba. 2009. Increasing dietary sugar concentration may improve dry matter intake, ruminal fermentation, and productivity of dairy cows in the postpartum phase of the transition period. J. Dairy Sci. 92:3341-3353. https://doi.org/10.3168/ jds.2008-1977.

Penner, G. B., M. Oba, G. Gäbel, and J. R. Aschenbach. 2010. A single mild episode of subacute ruminal acidosis does not affect ruminal barrier function in the short term. J. Dairy Sci. 93:48384845. https://doi.org/10.3168/jds.2010-3406.

Penner, G. B., M. A. Steele, J. R. Aschenbach, and B. W. McBride. 2011. Molecular adaptation of ruminal epithelia to highly fermentable diets. J. Anim. Sci. 89:1108-1119. https://doi.org/10.2527/ jas.2010-3378.

Pilachai, R., J. T. Schonewille, C. Thamrongyoswittayakul, S. Aiumlamai, C. Wachirapakorn, H. Everts, and W. H. Hendrik. 2012 Starch source in high concentrate rations does not affect rumen $\mathrm{pH}$, histamine and lipopolysaccharide concentrations in dairy cows. Livest. Sci. 150:135-142. https://doi.org/10.1016/j.livsci 2012.08.009.

Plaizier, J. C., E. Khafipour, S. Li, G. N. Gozho, and D. O. Krause. 2012. Subacute ruminal acidosis (SARA), endotoxins and health consequences. Anim. Feed Sci. Technol. 172:9-21. https://doi.org/ 10.1016/j.anifeedsci.2011.12.004.

Plaizier, J. C., D. O. Krause, G. N. Gozho, and B. W. McBride. 2008. Subacute ruminal acidosis in dairy cows: The physiological causes, incidence and consequences. Vet. J. 176:21-31.

Qumar, M., R. Khiaosa-Ard, P. Pourazad, S. U. Wetzels, F. Klevenhusen, W. Kandler, J. R. Aschenbach, and Q. Zebeli. 2016. Evidence of in vivo absorption of lactate and modulation of short chain fatty acid absorption from the reticulorumen of non-lactating cattle fed high concentrate diets. PLoS One 11:e0164192. https://doi.org/10 .1371/journal.pone.0164192.

Reis, L. F., R. S. Sousa, F. L. C. Oliveira, F. A. M. L. Rodrigues, C. A. S. C. Araújo, E. B. S. Meira-Júnior, R. A. Barrêto-Júnior, C. S. Mori, A. H. H. Minervino, and E. L. Ortolani. 2018. Comparative assessment of probiotics and monensin in the prophylaxis of acute ruminal lactic acidosis in sheep. BMC Vet. Res. 14:9. https://doi .org/10.1186/s12917-017-1264-4.

Rhoads, M. L., R. P. Rhoads, M. J. VanBaale, R. J. Collier, S. R Sanders, W. J. Weber, B. A. Crooker, and L. H. Baumgard. 2009. Effects of heat stress and plane of nutrition on lactating Holstein cows: I. Production, metabolism, and aspects of circulating somatotropin. J. Dairy Sci. 92:1986-1997. https://doi.org/10.3168/ jds.2008-1641.

Schlau, N., L. L. Guan, and M. Oba. 2012. The relationship between ruminal acidosis resistance and expression of genes involved in regulation of intracellular $\mathrm{pH}$ and butyrate metabolism of ruminal epithelial cells in steers. J. Dairy Sci. 95:5866-5875. https://doi .org/10.3168/jds.2011-5167.

Schurmann, B. L., M. E. Walpole, P. Górka, J. C. H. Ching, M. E. Loewen, and G. B. Penner. 2014. Short-term adaptation of the ruminal epithelium involves abrupt changes in sodium and shortchain fatty acid transport. Am. J. Physiol. Regul. Integr. Comp. 
Physiol. 307:R802-R816. https://doi.org/10.1152/ajpregu.00035 .2014 .

Schwaiger, T., K. A. Beauchemin, and G. B. Penner. 2013. The duration of time that beef cattle are fed a high-grain diet affects the recovery from a bout of ruminal acidosis: Short-chain fatty acid and lactate absorption, saliva production, and blood metabolites. J. Anim. Sci. 91:5743-5753. https://doi.org/10.2527/jas.2013-6472.

Schweigel, M., M. Freyer, S. Leclercq, B. Etschmann, U. Lodemann, A. Böttcher, and H. Martens. 2005. Luminal hyperosmolarity decreases $\mathrm{Na}$ transport and impairs barrier function of sheep rumen epithelium. J. Comp. Physiol. B 175:575-591.

Silberberg, M., F. Chaucheyras-Durand, L. Commun, M. M. Mialon, V. Monteils, P. Mosoni, D. P. Morgavi, and C. Martin. 2013. Repeated acidosis challenges and live yeast supplementation shape rumen microbiota and fermentations and modulate inflammatory status in sheep. Animal 7:1910-1920. https://doi.org/10.1017/ S1751731113001705.

Steele, M. A., O. Alzahal, M. E. Walpole, and B. W. McBride. 2012. Short communication: Grain-induced subacute ruminal acidosis is associated with the differential expression of insulin-like growth factor-binding proteins in rumen papillae of lactating dairy cattle. J. Dairy Sci. 95:6072-6076. https://doi.org/10.3168/jds.2011-4864.

Steele, M. A., J. Croom, M. Kahler, O. AlZahal, S. E. Hook, K. Plaizier, and B. W. McBride. 2011. Bovine rumen epithelium undergoes rapid structural adaptations during grain-induced subacute ruminal acidosis. Am. J. Physiol. Regul. Integr. Comp. Physiol. 300:R1515-R1523. https://doi.org/10.1152/ajpregu.00120.2010.

Steele, M. A., G. B. Penner, F. Chaucheyras-Durand, and L. L. Guan. 2016. Development and physiology of the rumen and the lower gut: Targets for improving gut health. J. Dairy Sci. 99:4955-4966. https://doi.org/10.3168/jds.2015-10351.

Stumpff, F. 2018. A look at the smelly side of physiology: Transport of short chain fatty acids. Pflugers Arch. 470:571-598. https://doi .org/10.1007/s00424-017-2105-9.

Stumpff, F., M. I. Georgi, L. Mundhenk, I. Rabbani, M. Fromm, H. Martens, and D. Günzel. 2011. Sheep rumen and omasum primary cultures and source epithelia: Barrier function aligns with expression of tight junction proteins. J. Exp. Biol. 214:2871-2882. https: //doi.org/10.1242/jeb.055582

Suber, R. L., J. F. Hentges, J. C. Gudat, and G. T. Edds. 1979. Blood and ruminal fluid profiles in carbohydrate-foundered cattle. Am. J. Vet. Res. 40:1005-1008.

Sun, X., X. Yuan, L. Chen, T. Wang, Z. Wang, G. Sun, X. Li, X. Li, and G. Liu. 2017. Histamine induces bovine rumen epithelial

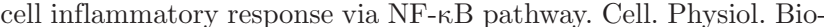
chem. 42:1109-1119. https://doi.org/10.1159/000478765.

Telle, P. P., and R. L. Preston. 1971. Ovine lactic acidosis: Intraruminal and systemic. J. Anim. Sci. 33:698-705.
Walpole, M. E., B. L. Schurmann, P. Górka, G. B. Penner, M. E. Loewen, and T. Mutsvangwa. 2015. Serosal-to-mucosal urea flux across the isolated ruminal epithelium is mediated via urea transporter-B and aquaporins when Holstein calves are abruptly changed to a moderately fermentable diet. J. Dairy Sci. 98:1204-1213. https:// doi.org/10.3168/jds.2014-8757.

Wilkens, M. R., C. Praechter, G. Breves, and B. Schröder. 2016. Stimulating effects of a diet negative in dietary cation-anion difference on calcium absorption from the rumen in sheep. J. Anim. Physiol. Anim. Nutr. (Berl.) 100:156-166. https://doi.org/10.1111/jpn .12296 .

Wilson, D. J., T. Mutsvangwa, and G. B. Penner. 2012. Supplemental butyrate does not enhance the absorptive or barrier functions of the isolated ovine ruminal epithelia. J. Anim. Sci. 90:3153-3161. https://doi.org/10.2527/jas.2011-4315.

Wood, K. M., S. I. Palmer, M. A. Steele, J. A. Metcalf, and G. B. Penner. 2015. The influence of age and weaning on permeability of the gastrointestinal tract in Holstein bull calves. J. Dairy Sci. 98:7226-7237. https://doi.org/10.3168/jds.2015-9393.

Zebeli, Q., and B. N. Ametaj. 2009. Relationships between rumen lipopolysaccharide and mediators of inflammatory response with milk fat production and efficiency in dairy cows. J. Dairy Sci. 92:3800-3809. https://doi.org/10.3168/jds.2009-2178.

Zebeli, Q., J. R. Aschenbach, M. Tafaj, J. Boguhn, B. N. Ametaj, and W. Drochner. 2012. Invited review: Role of physically effective fiber and estimation of dietary fiber adequacy in high-producing dairy cattle. J. Dairy Sci. 95:1041-1056. https://doi.org/10.3168/ jds.2011-4421.

Zebeli, Q., and B. U. Metzler-Zebeli. 2012. Interplay between rumen digestive disorders and diet-induced inflammation in dairy cattle. Res. Vet. Sci. 93:1099-1108.

Zhang, S., R. I. Albornoz, J. R. Aschenbach, D. R. Barreda, and G. B. Penner. 2013a. Short-term feed restriction impairs the absorptive function of the reticulo-rumen and total tract barrier function in beef cattle. J. Anim. Sci. 91:1685-1695. https://doi.org/10.2527/ jas. 2012-5669.

Zhang, S., J. R. Aschenbach, D. R. Barreda, and G. B. Penner. 2013b. Recovery of absorptive function of the reticulo-rumen and total tract barrier function in beef cattle after short-term feed restriction. J. Anim. Sci. 91:1696-1706. https://doi.org/10.2527/jas.2012 -5774 .

Zhao, C., G. Liu, X. Li, Y. Guan, Y. Wang, X. Yuan, G. Sun, Z. Wang, and X. Li. 2018. Inflammatory mechanism of rumenitis in dairy cows with subacute ruminal acidosis. BMC Vet. Res. 14:135. https: //doi.org/10.1186/s12917-018-1463-7. 